\title{
Kadın Sağlık Çalışanlarında Kültürel Değerler ile Kariyer Bağlılığı Arasındaki İlişkide Kariyer Memnuniyetinin Aracılık Rolü
}

\author{
The Mediating Role of Career Satisfaction in The Relation Between Career Commitment and \\ Cultural Values in Women Healthcare Employees
}

Muhammet Çankaya*

\begin{abstract}
Culture consists of many factors like language, religion, customs and habits, art, science, society, and history, which we call worldview or philosophy of life intertwined with each other. Culture also has an important role in the attitudes of people not only in their lifestyles, but also about the organizational elements in work life. As a result of the study conducted by Hofstede, who collected data from IBM employees in 76 countries to determine the differentiated cultural dimensions to identify societies, it was reported that culture has 6 dimensions in total. Career satisfaction, on the other hand, was defined by Kang et al. (2015) as the awareness of the individuals regarding their achievements in their current careers and their predictions for progress in future business life. Career commitment was defined by Mowday et al. (1982) as "the level of emotional commitment to a particular career", and as "attitude towards a profession or career" by Blau (1989). In this study, firstly, the perceptions of female healthcare employees regarding cultural values, career satisfaction and career commitment were measured. Then, the relation levels of these three variables with each other were examined. Finally, it was analyzed whether career satisfaction had a significant mediating effect in the relation between cultural values and career commitment. The study was conducted with 184 female healthcare employees working in public healthcare institutions and organizations in the city of Çankırl; and three different scales were used in the study. When the findings were interpreted, frequency and percentage analysis, reliability analysis, factor analysis, arithmetic mean and standard deviation values, correlation analysis and hierarchical regression analyses were made use of. As a result of the study, it was determined that the mean perception scores of female healthcare employees regarding cultural values, career satisfaction and career commitment were at "moderate" levels, there were significant relations among these three variables, and that the career satisfaction variable had a partial mediating effect in the relation between values and career commitment.
\end{abstract}

Structured Abstract: Introduction: The culture concept was defined by Hofstede (1991) as a collective mental programming distinguishing a group of people from others. Hofstede stated that culture is not hereditary and is learned in time. Hofstede defined the dimensions of culture in 6 levels. Among these, the Power Distance Dimension argues that weaker members of institutions and organizations accept and expect that power is not distributed evenly. This is a state of inequality. Titles, status, and position are considered important, and respected highly in cultures with high Power Distance scores. In working environment, the distance between

\footnotetext{
* Dr. Öğr. Üyesi, Hitit Üniversitesi, Sağlık Bilimleri Fakültesi, Sağlık Yönetimi Bölümü Asst. Prof. Dr. Hitit University, Faculty of Health Sciences, Department of Health Administration/ ORCID 0000-0003-3498-7328

muhammetcankaya@gmail.com, muhammetcankaya@ hitit.edu.tr

Cite as/ Atıf: Çankaya, M. (2020). Kadın sağlık çalışanlarında kültürel değerler ile kariyer bağl1lığı arasındaki ilişkide kariyer memnuniyetinin aracılı rolü, Turkish Studies - Social, 15(4), 1779-1804. https://dx.doi.org/10.29228/TurkishStudies.42733

Received/Geliş: 02 April/Nisan 2020

Accepted/Kabul: 20 June/Haziran 2020

Copyright $\odot$ INTAC LTD, Turkey
} 
the employee and the manager is prominent and protected. In societies with low power distance, on the other hand, the distribution of power among individuals is relatively more equal within the society. There is no social class differentiation and hierarchy (Çelikkol, 2019). Secondly, the Individualism-Collectivism Dimension is related to people in a country not preferring to act on their own to act as a group. The thing is, the interests of individuals are more important than the interests of the group in individualistic societies; however, in collectivist societies, compliance to the group and the interests of the group are above the interests of the individual (Öztürk, 2018). Hofstede et al. (2010) argued that when emotional gender roles are clearly distinguished in a society, in other words, if men are expected to focus on ambitious, harsh and material success, and women are expected to be more modest, sensitive and interested in quality of life, this particular society should be called masculine. In societies that exhibit feminine tendencies, the opposite pole of masculinity, emotional gender roles overlap, and it is expected that both men and women are modest, sensitive and interested in quality of life (Arslan, 2019). This dimension is considered as the third dimension of the culture, and is called as "the Masculinity-Femininity Dimension". The fourth dimension of culture is called "Avoidance of Uncertainty".

This dimension shows the degree of compliance of the group members in the face of unclear situations or in situations that are not defined explicitly. Dursun (2013) speculated that Sargut stated that individuals will try to increase job security, and written and formal rules in societies where avoidance of uncertainty is high, to make life safer for them. According to Dursun, there is a tendency to act according to the rules of the organization in these societies; and in other societies where there is less avoidance of uncertainty, innovations, changes and differences are not doubted. The $5^{\text {th }}$ dimension of culture is the Long-Short-Term Orientation Dimension. The Long-Term Orientation includes encouraging virtues like perseverance and prudence for future rewards. However, the Short-Term Orientation includes encouraging virtues related to the past and now, especially respect for tradition, the preservation of fame, and the fulfillment of social liabilities (Öztürk, 2018). The $6^{\text {th }}$ and final dimension of culture that was defined by Hofstede is the Eagerness-Constraint Dimension. The tendency to enjoy life and allow relatively free pleasure in basic and natural human desires for entertainment is defined as "enthusiasm". However, "constraint" is defined as the belief that such an "enthusiasm" should be constrained and regulated by strict social norms (Arslan, 2019).

Career Satisfaction, which was identified as the intermediary variable in the study, was defined by Kang et al. (2015) as the achievements of the individual in his/her current career and his/her awareness regarding his/her predictions for progress in future business life. Bayraktar (2019), on the other hand, defined career satisfaction as the positive psychological or work-related results or achievements obtained as a result of the experiences of individuals in working life.

Another variable, which was discussed in the study, was career commitment, and was defined by Mowday et al. (1982) as the emotional commitment level to a particular career; and as "the attitude towards a profession or career" by Blau (1989). Based on these definitions, career commitment can be briefly defined as individuals' attitudes towards their careers (Kaya, 2019).

Healthcare is an irrecusable service due to its unique nature (Çankaya, 2017; Tengilimoğlu et al., 2018). All actors in the healthcare sector spend great efforts to provide these services to the individuals who are in need for these services in the easiest way to reach the quality level they desire. Especially today, the efforts against the "Coronavirus-2019 Pandemic", which is called 2019-nCoV in scientific terms, and which is rapidly increasing in terms of prevalence on a global scale, show us with the full reality what healthcare employees do when performing their duties. Female employees in the healthcare sector also give a unique effort for this purpose.

\section{Methods}

No scientific studies were detected in the literature measuring the cultural perceptions, career satisfactions and career commitments of female employees, who are the "guardian angels" of the healthcare sector. To address this deficiency in the literature, it was considered beneficial to conduct this study with female healthcare employees who worked in public healthcare institutions in Çankırı province and who agreed to participate voluntarily in the questionnaire study. The number of female healthcare employees who participated in the questionnaire was 184. 
When the findings were interpreted, frequency and percentage analysis, reliability analysis, factor analysis, arithmetic mean and standard deviation values, correlation analysis and hierarchical regression analyses were made use of.

\section{Results}

A total of 12 hypotheses were created in line with the variables discussed in the present study. As a result of the analyses, 6 of these hypotheses were accepted, and the remaining 6 were rejected. To summarize the condition of the hypotheses, it is possible to argue that the power distance, collectivism and masculinity dimensions, which are among the dimensions of the cultural values, the independent variable of the study, have significant relations with the dependent variable, career commitment; and only the power distance dimension, which is among the cultural values dimension, i.e. the independent variable of the study, has a significant relation with career satisfaction intermediary variable. However, it is also seen as another result that the intermediary variable career satisfaction has a significant relation with the dependent variable career commitment. Finally, it is possible to speculate that the career satisfaction variable has a partial intermediary effect in the relation between cultural values and career commitment.

However, the present study also had some other purposes involved in addition to its main purpose. The first one was to determine the cultural value, career satisfaction and career commitment levels of female healthcare employees. As a result of the analyses made in this respect, the mean cultural value perception of female healthcare employees (general scale) was found to be 3.12. In other words, it is possible to argue that the cultural value perception levels of female healthcare employees are moderate. The highest participation among the cultural value dimensions scale was in the long-range dimension. This result may be interpreted as women healthcare employees consider long-term orientation virtues, especially perseverance and prudence, are relatively important than other cultural values. On the other hand, among the cultural values scale dimensions, the lowest level of participation was in power distance. This result may be interpreted as that social class differentiation and hierarchy are not seen as important in the cultural values of female healthcare employees. For the other variables in the study, the mean score was determined to be 2.98 for career satisfaction, and 2.90 for career commitment. This result show that the career satisfaction and career commitment perceptions of female healthcare employees involved in the study were at moderate levels.

Another purpose of the study was to determine whether there were significant relations between the cultural value, career satisfaction and career commitment perceptions of female healthcare employees. As a result of the correlation analysis made in this respect, it was found that there were some significant relations between the cultural value dimensions selected as the independent variables, and career satisfaction, which was considered to be the intermediary variable, and career commitment, which was considered as the dependent variable.

Another purpose of the present study was to determine whether the perceptions of female healthcare employees on the cultural values scale had significant effects on career commitment levels. In the multi-linear regression analysis made in this respect, it was determined that the dimensions of power distance $(.187$ and $p<0.01)$ and collectivity $(.250$ and $\mathrm{p}<0.01)$ had positive effects on career commitment, while avoidance of uncertainty dimension $(-.224$ and $\mathrm{p}<0.05)$ had a negative effect. However, it was also concluded that the long-range and masculinity dimensions of the cultural values scale had no significant effects on career commitment.

The final purpose in the study was to determine whether the perceptions of female healthcare employees in the cultural values scale had significant effects on career satisfaction levels. In the multi-linear regression analysis made in this respect, it was concluded that only the power distance dimension of the cultural values scale dimensions had significant effects on career satisfaction $(.174$ and $p<0.05)$; and the other dimensions had no significant effects.

Keywords: Career Satisfaction, Career Commitment, Cultural Values, Woman, Healthcare Employees.

Öz: Kültür; dil, din, örf ve adetler, sanat, bilim, toplum, tarih ve bunlarla yoğrulan bir dünya görüşü veya hayat felsefesi dediğimiz birçok faktörden meydana gelmektedir. Kültür aynı zamanda insanların sadece yaşam biçiminde değil onların çalışma hayatı içerisindeki örgütsel unsurlarla ilgili tavırlarında da önemli bir role sahiptir. Hofstede, toplumları tanımlamak için farklılaşan kültür boyutlarını belirlemek adına 76 ülkedeki IBM çalışanlarından veri toplayarak kültür üzerine yaptığı çalışmalar sonucunda kültürün toplamda 6 boyutu

www.turkishstudies.net/social 
olduğunu belirtmektedir. Kariyer memnuniyeti ise; Kang ve diğerleri (2015) tarafindan bireyin mevcut kariyerindeki başarıları ve gelecekteki iş yaşamında, ilerlemeye yönelik tahminlerine ilişkin farkındalığı olarak tanımlanmaktadır. Kariyer bağlılığ ise; Mowday ve diğerleri (1982) tarafından belli bir kariyere olan duygusal bağlılık seviyesi", Blau (1989) tarafından ise; "bir mesleğe ya da kariyere yönelik tutum" olarak tanımlamaktadır. Bu çalışmada ilk olarak kadın sağlık çalışanlarının kültürel değerler, kariyer memnuniyeti ve kariyer bağlılığı konularındaki algıları ölçülmüştür. Daha sonra bu üç değişkenin birbirleri ile olan ilişki düzeyleri incelenmiştir. Son olarak kariyer memnuniyetinin, kültürel değerler ile kariyer bağlılığ 1 arasındaki ilişkide anlamlı bir aracılık etkisinin olup olmadığı analiz edilmiştir. Çalışma, Çankırı ilindeki kamuya ait sağlık kurum ve kuruluşlarında görev yapan 184 kadın sağlık çalışanı ile gerçekleştirilmiş ve çalışmada üç farklı ölçek kullanılmıştır. Bulgular yorumlanırken; frekans ve yüzde analizi, güvenilirlik analizi, faktör analizi, aritmetik ortalama ve standart sapma değerleri, korelasyon analizi ve hiyerarşik regresyon analizlerinden yararlanılmıştır. Çalışma sonucunda; kadın sağlık çalışanlarının kültürel değerler, kariyer memnuniyeti ve kariyer bağlılığına ilişkin algı ortalamalarının "orta düzeyde" olduğu, incelenen bu üç değişken arasında anlamlı ilişkilerin olduğu ve kariyer memnuniyeti değişkeninin, kültürel değerler ile kariyer bağlılığı arasındaki ilişkide kısmi aracılık etkisinin olduğunu tespit edilmiştir.

Anahtar Kelimeler: Kariyer Memnuniyeti, Kariyer Bağlılığı, Kültürel Değerler, Kadın, Sağlık Çalışanları.

\section{Giriş}

İnternet ve haberleşme teknolojilerinin hızla gelişmesi ile birlikte günümüz örgütlerinin birçoğu ticari faaliyetlerini küresel çapta sürdürmektedir. Bilgi çağında ticari faaliyetlerin ulusal boyuttan küresel boyuta geçişi ile birlikte insan hareketlililği de artmış ve toplumlardaki kültürel çeşitliliğin farkına varılmıştır. Bu gelişmeye karşın Sargut (1994), küreselleşme ile birlikte evrensel kültür değerlerinin tüm dünyaya yayılacağı ve böylece ortak bir insanlık kültürünün oluşacağı gibi bir beklentinin varlığından söz etmektedir. Ancak bu beklentinin gerçekleştiğini söylemek bugün için olası değildir. Şu ana kadar küreselleşme, ulusçuluk eksenli çatışmaları durduramadığı gibi etnik, kültürel ve ekonomik boyutlu bölgeselcilik ile beslenen yapılanmaları da önleyememiştir (Çağlar, 2001). Günümüzde, toplumlar arasındaki kültürel çeşitlilikler hala devam etmekte ve bu çeşitliliklerden doğan farklılıklar da örgüt ve insan temalı çalışmalar için ilgi odağı haline gelmektedir.

Kültür; dil, din, örf ve adetler, sanat, bilim, toplum, tarih ve bunlarla yoğrulan bir dünya görüşü veya hayat felsefesi dediğimiz birçok faktörden meydana gelmektedir. Arı (1999), kültürel faktörlerin bireylerin davranışlarında bazı etkilerinin olduğunu ifade etmektedir. Örnek olarak da Rusların kaba kuvvetçiliği ve inatçıllğını, Amerikalıların bireysel girişim ve buluşçuluğunu, Almanların disiplin ve kabalığı'nı dile getirmektedir (Asunakutlu ve Safran, 2004).

Bireylerin fiziksel ve toplumsal çevrelerine uyum sağlayabilmek amacıyla yaratıkları maddi ve manevi eserlerin bütünü (Güçlü, 2003) olarak tanımlanan kültür; aynı zamanda insanların sadece yaşam biçimine değil onların çalışma hayatı içerisindeki örgütsel unsurlarla ilgili tavırlarında da önemli bir role sahiptir. Yüksel (1989), birbirinden farklı çevrelerde ve farklı yapılarda faaliyet gösteren örgütlerin küreselleme ile birlikte sosyo-kültürel yapılarında bazı değişimlerin yaşandığını, örgüt çalışanları arasında kültürel farklılıkların meydana geldiğini ve bu farklılıkların örgüt yöneticileri için önemini arttırdığını belirtmektedir.

Kadınların istihdam ve terfilerinde sadece örgüt kültürü değil, toplumsal ve kültürel değerlerin, sosyal kalıpların ve normların etkileri de önemli bir engel olarak görülmektedir (Örücü vd., 2007). Yüzyıllardır süregelen bir süreçte kadın, sosyal yaşamda kendine aile ve ev içerisinde yer bulmuştur. Toplumsal yaşamda ev odaklı işler kadınlara doğal bir işbölümü olarak paylaştırılmıştır. Bu durum ise kadınları bireysel kazancın dışında bırakmıştır (Karabıyık, 2012). Ergüder'den (2006) aktaran Kılınç (2015), kadının çalışma hayatı içinde yer edinmesinin ve kadın emeği kavramının Türkiye'de kullanılmasının, kentleşme süreci ile birlikte ortaya çıtığını ifade etmektedir. Türkiye'deki köylerde herhangi bir ücret almadan "aile işçisi”" olarak çalışan kadınlar, yirminci 
yüzyılın ikinci yarısından itibaren iç göç ve sanayi merkezlerinin ortaya çıkışıyla beraber özellikle sanayileşen bölgelerde ev dışında ücretli işlerde çalışmaya başlamışlardır (Kılınç, 2015). Öztürk ve diğerleri (2017) kadınların işgücüne katılımlarının, temel ihtiyaçlarını karşılayabilmelerinin, yaşadıkları hayattan tatmin ve mutlu olmalarının, yani yaşam kalitelerinin ülkelerin refahı açısından oldukça önemli olduğunu ifade etmektedirler. Bu doğrultuda kadın çalışanların işgücünde kalabilmeleri adına kariyer memnuniyeti ve kariyer bağlılığı gibi kavramların önemli olduğu düşünülmektedir.

$\mathrm{Bu}$ çalışmada öncelikle kültürel değerler ve Hofstede tarafindan ele alınan kültür boyutları, kariyer memnuniyeti ve kariyer bağlılığı gibi kavramlar açıklanmıştır. Çalışmada daha sonra Çankırı ilindeki kamuya ait sağlık kurum ve kuruluşlarında görev yapan kadın sağlık çalışanlarının kültürel değerler, kariyer memnuniyeti ve kariyer bağlılıklarına yönelik algıları ölçülmüştür. Ayrıca çalışmada; bu üç değişkenin birbirleri ile olan ilişkileri de incelenmiş̧ir. Son olarak kariyer memnuniyetinin, kültürel değerler ile kariyer bağlılı̆̆ arasındaki ilişkide anlamlı bir aracılık etkisinin olup olmadığı analiz edilmiştir. Alanyazın tarandığında bu üç değişkenin diğer örgütsel kavramlar ile ayrı ayrı ele alındığ 1 çalışmalar bulunmasına rağmen, birlikte ele alındıkları bir çalışmanın olmadığı görülmüş̧ür. Bu açıdan bakıldığında yapılan bu çalışmanın alanyazına önemli bir katkı sağlayacağı düşünülmektedir.

\section{Kavramsal Çerçeve}

Araştırmanın bu bölümünde; kültürel değerler, kariyer memnuniyeti ve kariyer bağl1lığı kavramlarına ilişkin bilgilere yer verilmektedir.

\section{Kültürel Değerler}

Kültür kavramı Hofstede (1991) tarafından "bir insan grubunu, diğerlerinden ayıran kolektif zihinsel programlama" şeklinde tanımlamaktadır. Hofstede, kültürün kalıtsal olmadığını, zaman içinde öğrenildiğini belirtmektedir. Hofstede, toplumları tanımlamak amacıyla farklılaşan kültür boyutlarını belirlemek için 76 ülkede görev yapan IBM çalışanlarından veri toplayarak kültür üzerine yaptığı çalışmalar sonucunda ilk olarak kültürün 4 boyutu olduğunu belirtmektedir. Ancak ileriki yıllarda batılı olmayan toplumlar için de bu tür çalışmalar yapmış ve kültüre 2 boyut daha eklemiştir (Küçükkömürler ve Kırımer-Aydınlı, 2019; Arslan, 2019). Kültür boyutlarını şu şekilde açıklamak mümkündür:

1. Güç mesafesi: Bu boyut; kurumlar ve organizasyonların daha güçsüz üyelerinin gücün eşit dağılmadığını kabullendiği ve bunu beklediğini ifade eder. Bireysel düzeydeki güç mesafesi ise; "bireyin, kurum ve organizasyonlarıdaki eşit olmayan güç dağılımını ne ölçüde kabul ettiği anlamına gelmektedir. Bu bir eşitsizlik durumudur. Güç mesafesinin yüksek olduğu kültürlerde; unvan, statü, pozisyon gibi tasviri ögelere daha fazla önem verilmekte ve saygı duyulmaktadır. Güç mesafesinin yüksek olduğu kültürlerde var olan örgütsel yaşam içerisinde ise; çalışan ve yönetici arasındaki mesafe belirgin durumdadır ve bu mesafe korunmaktadır. Bunun aksine güç mesafesinin düşük olduğu toplumlarda ise bireyler arasında gücün dağılımı göreceli olarak daha eşit düzeydedir. Toplumsal yaşamda sınıf ayırımı ve hiyerarşi bulunmamaktadır (Farh vd., 2007; Çelikkol, 2019). Toruntay (2019) tarafından Hofstede'nin Güç Mesafesi İndeksi'ne göre 78 ülke için hazırlanan Global Güç Mesafesi Haritası Şekil-1'de gösterilmektedir. 


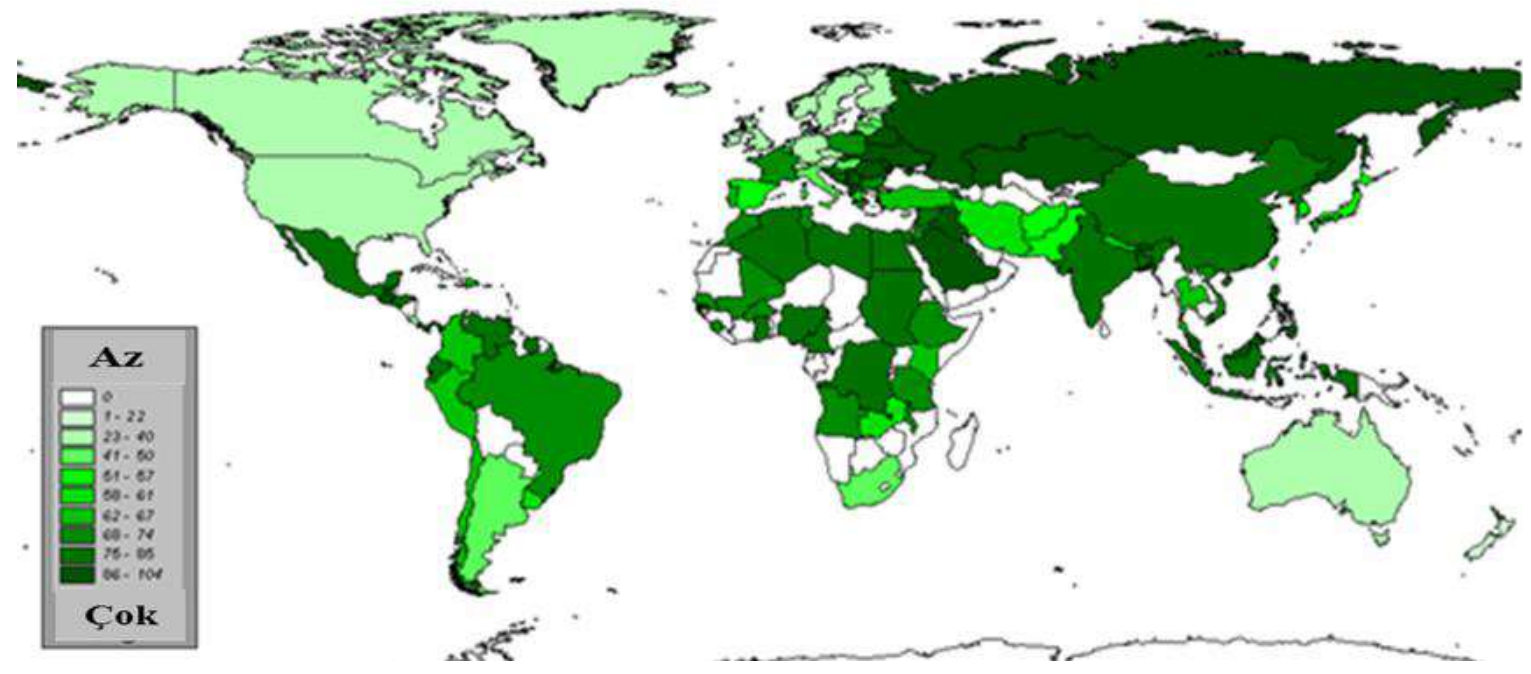

Şekil-1. Global Güç Mesafesi Haritası

Şekil-1'deki renkler koyulaştıkça toplumdaki güç mesafesi artmaktadır. Haritada Doğu'ya doğru gittikçe renklerin koyulaştı̆̆ı, yani toplumlar arasındaki güç mesafesi boyutunun arttı̆̆ görülmektedir (Toruntay, 2019). Saylık (2019) ise; Avustralya, İsrail, Danimarka, İrlanda, Norveç ve İsveç gibi ülkelerin düşük güç mesafesi, Malezya, Suudi Arabistan ve Meksika gibi ülkelerin ise yüksek güç mesafesi özelliğine sahip ülkeler olduğunu belirtmektedir.

2. Bireycilik ve kolektivizm: Kültür boyutları içerisindeki en önemli boyut olarak değerlendirilen bireycilik-kolektivizm boyutu; bir toplumdaki bireylerin kendi başlarına hareket etmeyi, grup olarak hareket etmeye tercih edip etmemeleri ile ilgilidir. Bireycilik özelliği daha baskın olan toplumlarda bireylerin çıkarları grubun çıkarlarından daha önemlidir, ancak kolektivist özelliği daha baskın olan toplumlarda ise; gruba uyum ile grubun çıkarlarının bireyin çıkarlarına göre üstünlüğü daha önemli görülmektedir (Öztürk, 2018). Toruntay (2019) tarafindan Hofstede'nin Bireyselcilik-Toplulukçuluk İndeksi'ne göre 78 ülke için hazırlanan Bireycilik ve Kolektivizm Haritası Şekil-2'de gösterilmektedir.

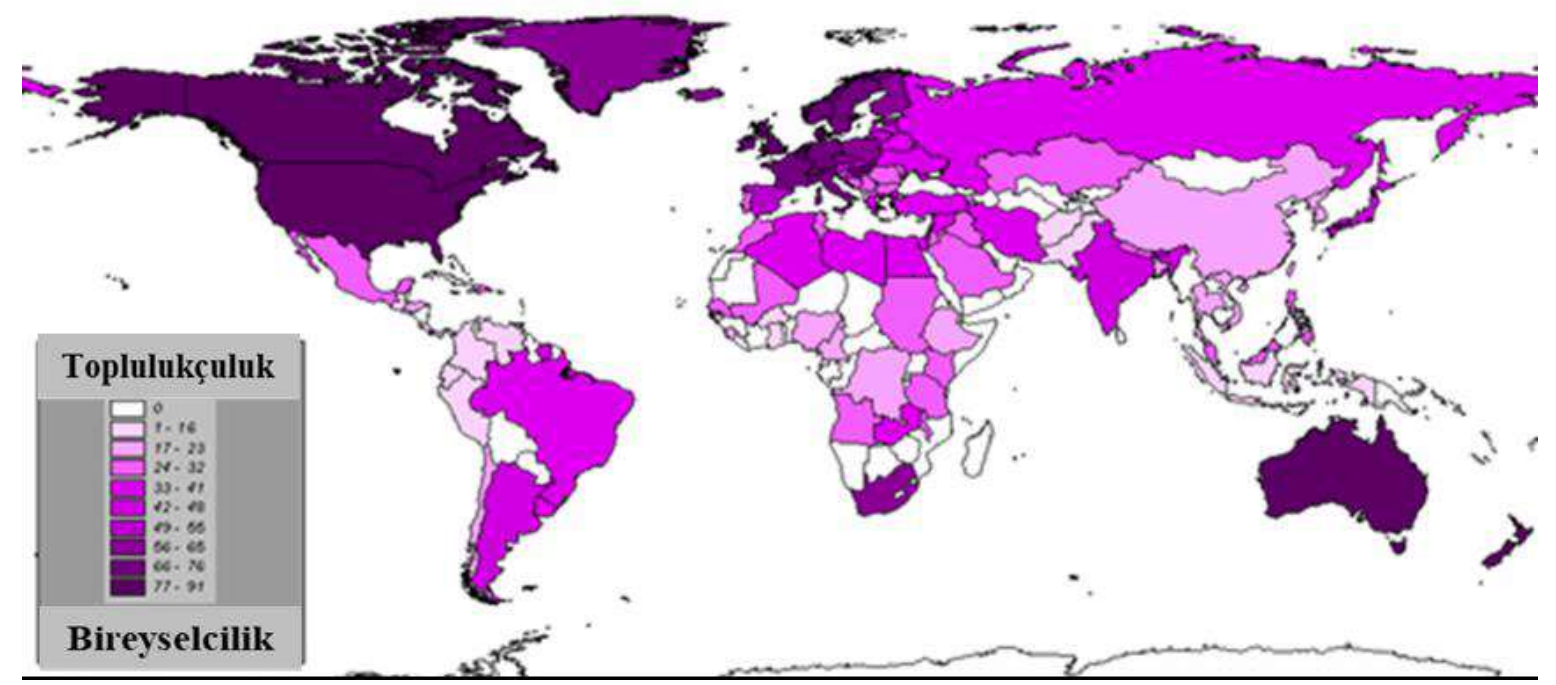

Şekil-2. Bireycilik ve Kolektivizm Haritası 
Şekil-2'deki renkler koyulaştıkça toplumdaki bireycilik artmaktadır. Haritada Batı'ya doğru gidildikçe renklerin genel olarak koyulaştığı yani toplumlar arasındaki bireycilik boyutunun arttığı görülmektedir (Toruntay, 2019). Saylık (2019) ise; Japonya, Kore, Endonezya, Pakistan ve Latin Amerika gibi ülkelerin kolektivizm, ABD, Kanada, Avustralya, İngiltere, Hollanda, İtalya ve İskandinav Ülkeleri gibi ülkelerin ise bireycilik özelliğine sahip ülkeler olduğunu belirtmektedir.

3. Erillik ve dișilik: Hofstede vd. (2010), bir toplumda duygusal cinsiyet rolleri açıcça ayırt edildiğinde, yani erkeklerin iddialı, sert ve maddi başarıya odaklanmaları beklenirken, kadınların daha mütevazı, hassas ve yaşam kalitesiyle ilgileniyor olması bekleniyor ise, o toplumun eril olarak adlandırılması gerektiğini belirtmektedir. Erilliğin karşıtı olan dişilik özelliği gösteren toplumlarda ise, duygusal cinsiyet rolleri üst üste gelmiş, hem erkeklerin hem de kadınların mütevazı, hassas ve yaşam kalitesiyle ilgileniyor olmaları beklenir (Arslan, 2019). Ay (2005) ise; erillik özelliğine sahip kültürlerde rekabet, kazanç, performans gibi kavramların öne çıktığını, buna karşın dişilik özelliğine sahip kültürlerde ise yaşam kalitesi, çevre duyarlılığı, korunmaya muhtaç olanların korunması ve dayanışma gibi değerlerin öne çıktığını belirtmektedir. Toruntay (2019) tarafindan Hofstede'nin Kadınlık-Erkeklik İndeksi'ne göre 78 ülke için hazırlanan Erillik ve Dişilik Haritası Şekil-3'de gösterilmektedir.

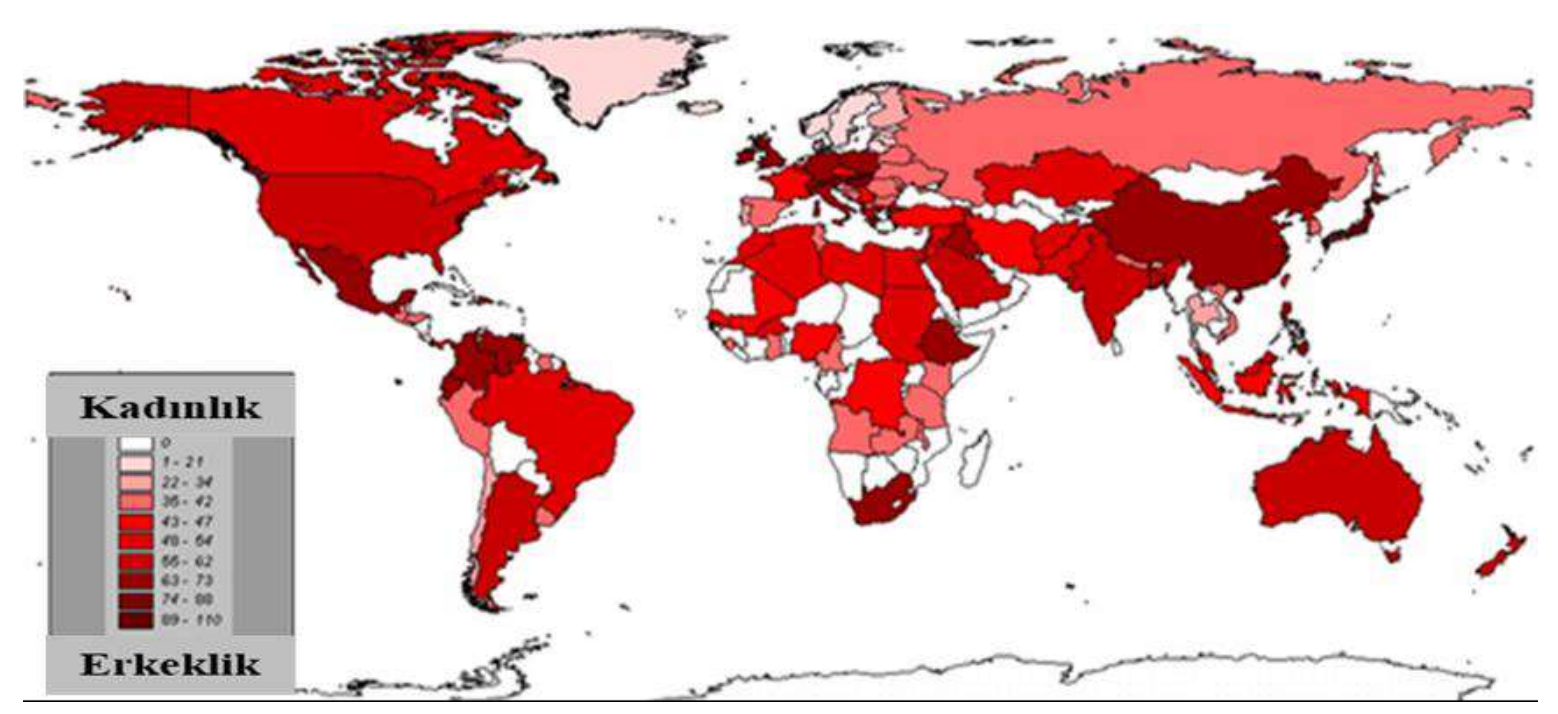

Şekil-3. Erillik ve Dişilik Haritası

Şekil-3'deki renkler koyulaştıkça toplumdaki erillik artmaktadır. Haritada Kuzey'e doğru gidildikçe, renklerin genel olarak daha soluklaştığı yani Kuzey'deki toplumlar arasındaki dişilik boyutunun arttığı görülmektedir (Toruntay, 2019). Saylık (2019) ise; Japonya, Avusturya, İsviçre, İtalya ve Meksika gibi ülkelerin erillik, Hollanda, İsveç, Norveç ve Kosta Rika gibi ülkelerin ise dişilik özelliğine sahip ülkeler olduğunu belirtmektedir.

4. Belirsizlikten kaçınma: Hofstede vd. (2010) tarafindan bu boyut; yazılı ve yazılı olmayan kurallara olan ihtiyaç biçiminde ifade edilmektedir. Bununla birlikte belirsizlikten kaçınma; grup üyelerinin belirsiz veya açıkça tanımlanıp yapılandırılmamış durumlara karşı ne derecede uyum sağlayabildiklerini göstermektedir. Toplumsal yaşamı düzenleyen resmi kuralların ve kontrol sistemlerinin çokluğu, standart prosedür ve planlar, uzmanlık ve kariyer sisteminin sürekliliğine verilen önem, bireylerin risk alma eğilimleri, çoğunluğun eğilimlerinden sapma gösteren düşünce ve davranış biçimlerine karşı anlayış düzeyi belirsizlikten kaçınma seviyesi düşük veya yüksek olan kültürlerde farklılaşmaktadır (Sığrı ve Tığl1, 2006). Sargut'tan (2001) aktaran Dursun (2013), belirsizlikten kaçınmanın yüksek olduğu toplumlarda bireylerin, yaşamı kendileri için daha güvenli 
bir duruma getirmek amacıyla iş güvencesini, yazılı ve biçimsel kuralları artırmaya çalışacaklarını belirtmektedir. Dursun'a göre; belirsizlikten kaçınmanın yüksek olduğu toplumlarda, örgüt kurallarına göre hareket etmek söz konusuyken, belirsizlikten kaçınmanın az olduğu toplumlarda ise; yeniliklere, değişikliklere ve farklılıklara şüphe ile balmama durumu hakimdir. Toruntay (2019) tarafından Hofstede'nin Tolere Etme-Kaçınma İndeksi'ne göre 78 ülke için hazırlanan Belirsizlikten Kaçınma Haritası Şekil-4'de gösterilmektedir.

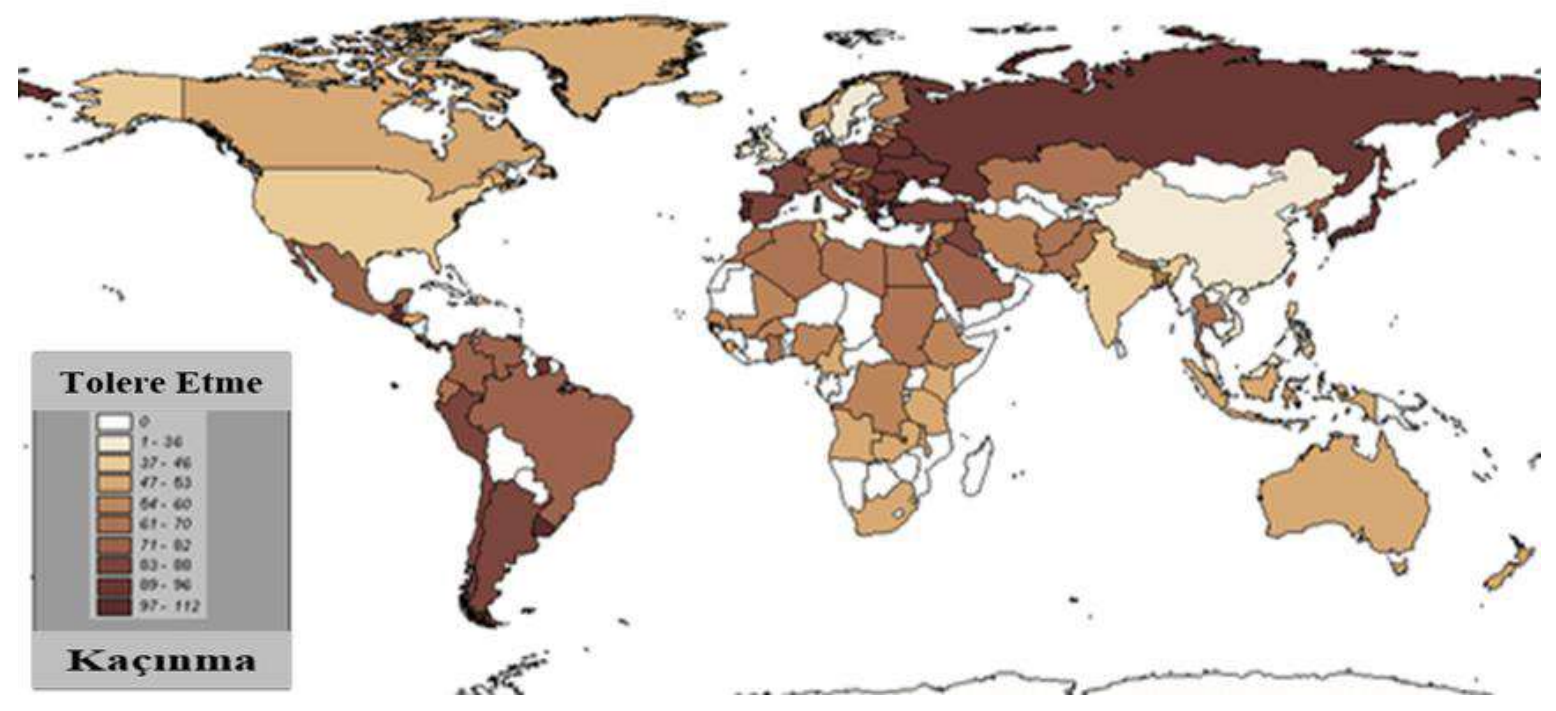

Şekil-4. Belirsizlikten Kaçınma Haritası

Şekil-4'deki renkler koyulaştıkça toplumdaki belirsizlikten kaçınma artmaktadır (Toruntay, 2019). Haritada renklerin dağılımlarına bakıldığında Rusya Federasyonu ve Doğu Avrupa ülkelerinde belirsizlikten kaçınma düzeyinin yüksek olduğu, diğer coğrafi bölgelerde ise dağılımların oldukça farklılık gösterdiği görülmektedir. Saylık (2019) ise; Singapur, Jamaika, Danimarka, İsveç ve İngiltere gibi ülkelerin tolere etme (belirsizliğe karşı tahammül edebilen), Japonya, Fransa, Uruguay, İspanya, Portekiz ve Yunanistan gibi ülkelerin ise belirsizlikten kaçınma (belirsizliğe karşı tahammül edemeyen) özelliğine sahip ülkeler olduğunu belirtmektedir.

5. Uzun vadeli yönelim ve kısa vadeli yönelim: Bu boyut, bireyin yaşantısındaki olaylara karşı olan tutumları ile ilgilidir. Uzun vadeli yönelim; gelecekteki ödüllere ilişkin özellikle bazı erdemlerin teşvik edilmesini içermektedir. Bu erdemler ise; azim ve tutumluluk olarak belirlenmiştir. Buna karşın kısa vadeli yönelim ise; geçmişe ve şimdiye ilişkin, özellikle geleneğe saygı, ünün korunması ve toplumsal yükümlülüklerin yerine getirilmesi gibi erdemlerin teşvik edilmesini içermektedir (Öztürk, 2018). Toruntay (2019) tarafından Hofstede'nin Uzun Dönem-Kısa Dönem İndeksi'ne göre 66 ülke için hazırlanan Uzun Vadeli Yönelim ve Kısa Vadeli Yönelim Haritası Şekil5 'de gösterilmektedir. 


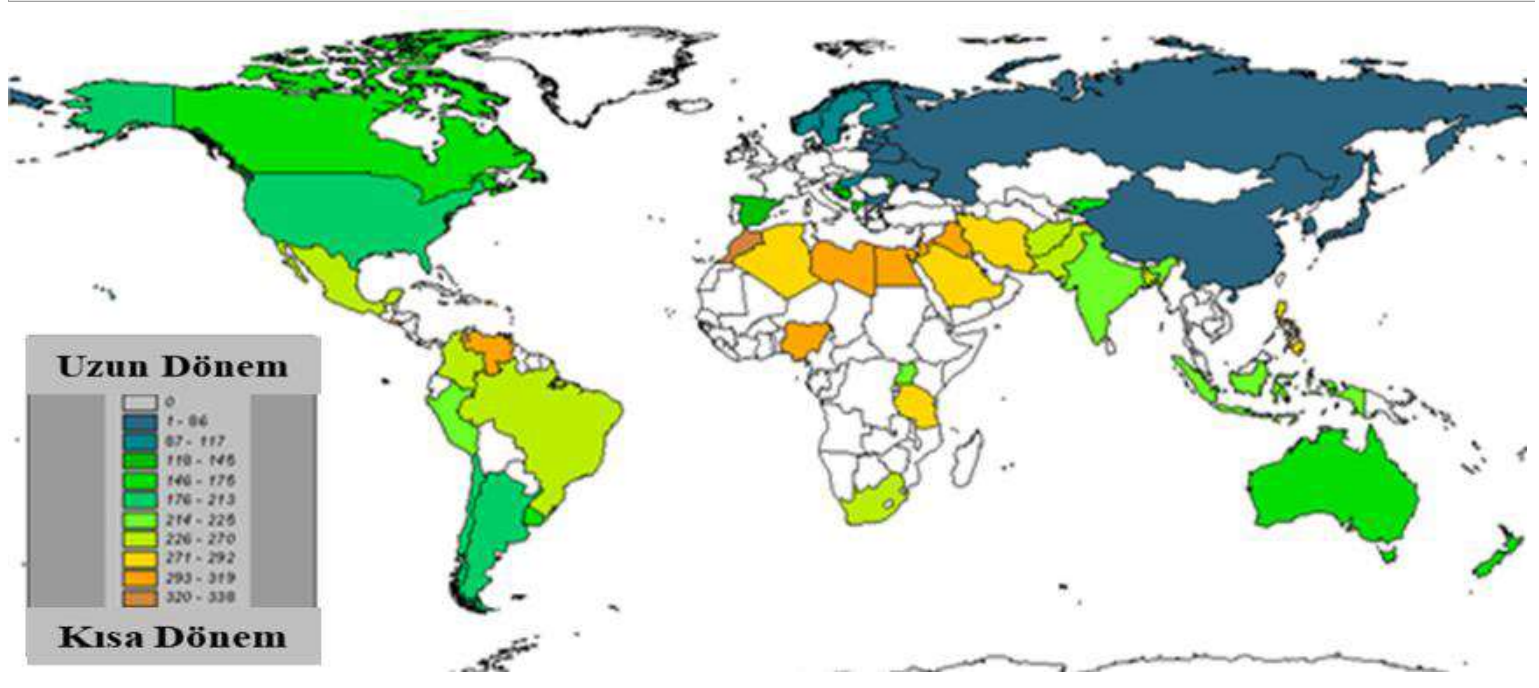

\section{Şekil-5 Uzun Vadeli Yönelim ve Kısa Vadeli Yönelim Haritası}

Şekil-5'deki renkler koyulaştıkça toplumdaki uzun vadeli yönelim değeri artmaktadır. Haritada Doğu'ya doğru gidildikçe renklerin genel olarak koyulaştığı yani Doğu Asya toplumlarında uzun vadeli yönelim boyutunun arttığı görülmektedir (Toruntay, 2019). Buna karşın Ortadoğu ve Kuzey Afrika ülkelerinde kısa vadeli yöneliminin olduğu söylenebilir. Saylık (2019) ise; Japonya, Kore, Çin ve Brezilya gibi ülkelerin uzun vadeli yönelim, Rusya, Nijerya, Pakistan ve Filipinler gibi ülkelerin ise kısa vadeli yönelim özelliğine sahip ülkeler olduğunu belirtmektedir.

6. Heveslilik-kısıtlık: Hayattan zevk almak ve eğlenmekle ilgili temel ve doğal insan arzuları için nispeten serbest bir şekilde haz duyulmasına izin verme eğilimi "heveslilik" olarak tanımlanmaktadır. Buna karşın "kısıtlılık" ise; bu tür bir haz duymanın katı sosyal normlar tarafindan dizginlenmesi ve düzenlenmesi gerektiği inancı biçiminde tanımlanmaktadır (Arslan, 2019). Toruntay (2019) tarafından Hofstede'nin Heveslilik-Kısıtll1ık İndeksi'ne göre 66 ülke için hazırlanan Heveslilik-Kısıtlılık Haritası Şekil-6' da gösterilmektedir.

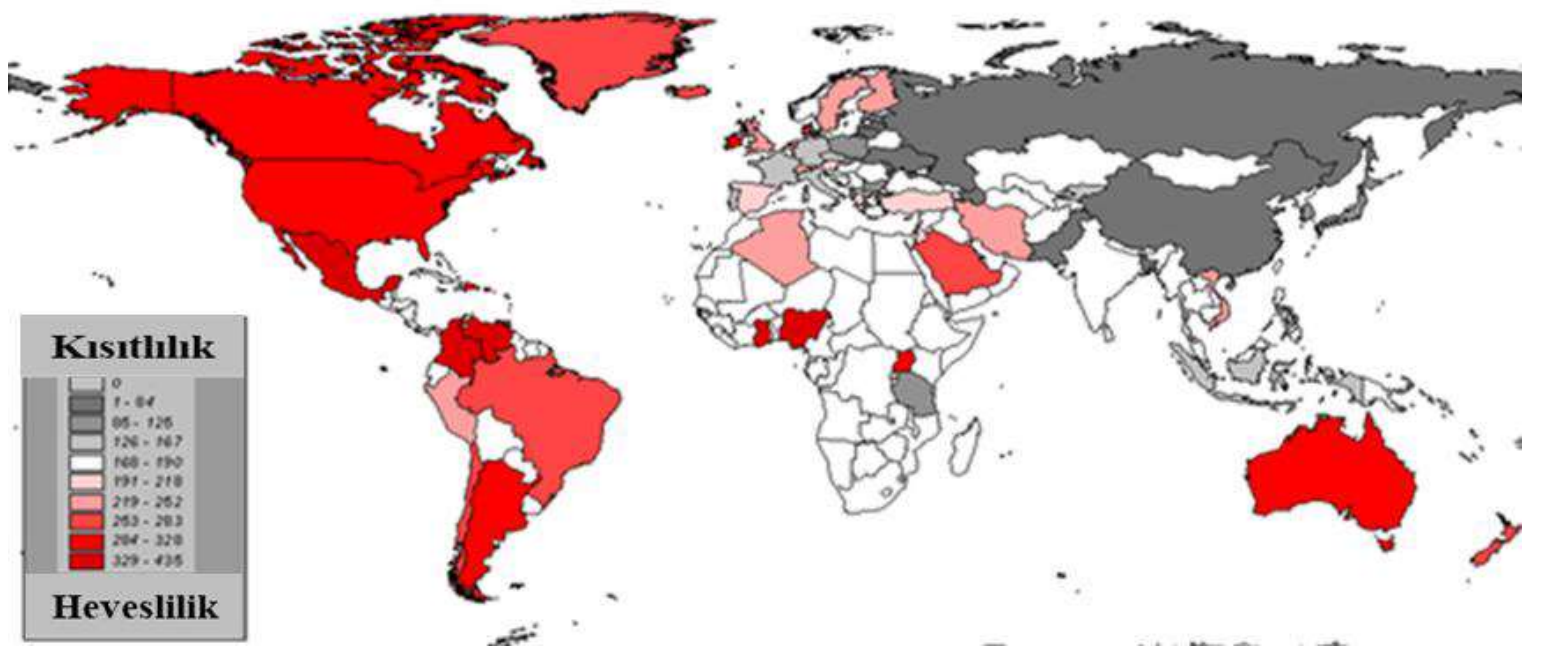

Şekil-6 Heveslilik-Kısıtlıık Haritası

Şekil-6'daki renkler koyulaştıkça toplumdaki heveslilik değeri artmaktadır. Haritada özellikle Güney ve Kuzey Amerika, Avustralya, Sub-Sahran Afrika, Asya ve Müslüman ülkelerinin 
bir kısmında heveslilik boyutunun hakim olduğu görülmektedir. Buna karşın Pakistan, Çin, Rusya, Letonya, Litvanya ve Bulgaristan gibi ülkelerde ise kısıtlılık boyutu ön plana çıkmaktadır (Toruntay, 2019).

Hofstede tarafından yapılan kültür araştırmalarına dayanarak Sargut (1994) tarafindan ülkemizde gerçekleştirilen bir araştırmada Türk kültürüne ilişkin bir takım bulgular elde edilmiştir. $\mathrm{Bu}$ çalışma sonucunda Türk kültürüne ilişkin yapılan tespitler ise şu şekilde sıralanmaktadır (Ay, 2005):

- Türk kültürü; ortaklaşa davranışı, bireyciliğin önünde tutmaktadır.

- Türk kültürü; sanıldığ1 gibi çağ dış1 sayılabilecek geleneksel erkek değerler sisteminin egemenliği altında değildir.

- Türk kültüründe; belirsizlikten kaçınma eğilimi yüksektir.

- Türk kültürü; denetim noktası dışarıda olan bireyleri üretir.

- Türk kültürünün; örgütsel güç mesafesi fazladır.

- Türk kültürü; uzlaşmadan ve yarışmadan kaçınmayı özendirir.

- Türk toplumu; geniş bağlamlı bir kültürün içinde yaşamaktadır.

Aydın ve Uçman (2019) da Türk toplumunun çalışma yaşamındaki özelliklerini Hofstede'nin boyutları açısından şu şekilde tasvir etmişlerdir:

- Kültür denildiğinde; Türk toplumunda değerler, gelenek-görenekler ve yaşam biçimi ön plana çıkmaktadır.

- Türk toplumunda statü sahibi kişilere ayrıcalık tanınır ve bu nedenle güç mesafesi yüksektir.

- Türk toplumunda örgüt içerisindeki iletişim kuvvetli, hiyerarşi ve yapılan işlerde belirsizlikler mevcuttur. Ayrıca yazılı kurallar duruma göre esnetilebilir.

- Türk toplumundaki yönetici özelliklerinde; adil olma, babacan tavır, iletişime açık olma, işini iyi bilme, vicdanlı olma, otoriter olma ve liderlik gibi faktörler etkilidir.

- Türk toplumunda yöneticilerin karar verme tarzlarına bakıldığında ise; çıkarlar, sosyal çevre, gelenek-görenek ve para etkilidir.

- Kariyer ilerleme faktörlerinde; kayırma ve planlı çalışma faktörleri iş yaşamını etkilemektedir.

- Örgütsel özellikler açısından; iletişim, hiyerarşi, kurallarda esneklik, belirsizlik ve ödül-ceza sistemleri etkindir.

- Sosyo-çevresel faktörlerde; maddiyat ön planda, statü sahibi kişilere ayrıcalık tanınması gerektiğine olan inanç ve bencillik hakimdir.

- Kişilerarası ilişkilerde rekabet ön plandadır.

\section{Kariyer Memnuniyeti}

Kang ve diğerleri (2015) kariyer memnuniyetini; bireyin mevcut kariyerindeki başarıları ile gelecekteki iş yaşamında ilerlemeye yönelik tahminlerine ilişkin farkındalığ 1 olarak tanımlarken, Bayraktar (2019) ise; bireylerin çalışma yaşamında elde ettiği tecrübelerin sonucunda ortaya çıkan olumlu psikolojik ya da iş ile ilgili sonuç veya başarılar şeklinde tanımlamaktadır.

Kariyer memnuniyeti ile ilgili yapılan çalışmaların önemli bir kısmı Vroom'un beklenti kuramı ile kişi-çevre uyumu teorisine dayanmaktadır. Vroom'un beklenti kuramı, bireyin kariyer 
memnuniyeti ile ilgili bazı açıklamalar getirmektedir. Beklenti kuramına göre birey, zevklerini artırma ve sıkıntılarından kaçınma arzusu içerisindedir. Birey, işinden ve işyerindeki konumundan zevk alıyorsa yüksek düzeyde kariyer memnuniyetine sahip olacaktır. Bireyin kariyer memnuniyetine ilişkin diğer bir açıklama da kişi-çevre uyumu teorisine aittir. Bu teoriye göre kariyer memnuniyeti; bireylerin kültürleri, ihtiyaçları, tercihleri ve yetenekleri ile çalıştıkları örgüt yapıları, iş yerinde kullandıkları kaynaklar, ödüller ve rollerin uyumuna bağlı olarak oluşmaktadır. Bireyler, çalıştıkları örgütlerde bu uyumu hissedebildiklerinde kariyer memnuniyetleri de yüksek düzeyde olacaktır (Çelik, 2012). Örgütteki bir çalışanın, yüksek düzeyde kariyer memnuniyetine sahip olması durumunda bulunduğu kariyer seviyesinde kalabilmek için elinden geleni yapacağı ifade edilmektedir. Bu durumda çalışan, kendisinin ve örgütün etik seviyelerine bağlı olarak örgüt için değerli ve önemli olan her türlü davranış1 sergileyebilecektir (Çelik vd., 2014).

Örgütsel yaşam içerisinde kariyer memnuniyetinin örgütsel bağll1ık, örgütsel değişimi destekleme, örgütte kalma isteği, maaş ve hiyerarşik seviye gibi örgütsel unsurlar ile pozitif yönde ilişkilerinin olduğu, buna karşın işten ayrılma niyeti ile negatif yönde ilişkisinin olduğu ifade edilmektedir (Kaya, 2018).

\section{Kariyer Bağlılığı}

Çalışmada ele alınan diğer bir değişken de kariyer bağlılı̆̆ıdır. Kariyer bağlılığı; Mowday ve diğerleri (1982) tarafindan belli bir kariyere olan duygusal bağlllık seviyesi”, Blau (1989) tarafından ise; "bir mesleğe ya da kariyere yönelik tutum" olarak tanımlamaktadır. Bu tanımlardan hareketle kariyer bağlılığını; bireylerin kariyerlerine ilişkin tutumları şeklinde kısaca tanımlamak mümkündür (Kaya, 2019).

Bireyin pozisyonuna ilişkin algılamalarını kapsayan kariyer bağlılığı, aynı zamanda bireyin kariyer ilerlemesini ve gelişimini önemli olarak değerlendirdiği bir durumdur. Bir çalışanda yüksek düzeyde kariyer bağlılığı olması durumunda çalışan, kariyer hedeflerini doğru tespit edebilir ve bu hedeflere ulaşmak için çaba sarf ederek motive olabilir (Şimşek ve Çelik, 2012).

Kariyer bağl1lığının örgütsel bağl1lık ve işe bağl1lık gibi örgütsel unsurlar ile pozitif yönde, ancak işten ayrılma niyeti ve iş devir hızı gibi örgütsel unsurlarla da negatif yönde ilişkilerinin olduğu belirtilmektedir (Kaya, 2018).

Kariyer bağlılığını bir tutum olarak değerlendiren Özdevecioğlu ve Aktaş (2007), bireylerin kariyerlerine bağlılığının üç temel nedeni olduğunu ifade etmektedirler. Bu nedenleri ise şu şekilde siralamaktadirlar:

1. Kariyer; bireyin geleceğini ifade eder, bireyler vizyonlarının bir gereği olarak kariyerlerine bağlı olurlar,

2. Kariyer; bireyin statüsünün gelişmesini ifade eder, aynı zamanda statü sembolüdür. Birey, bu sembolü iş dışı yaşamında da kullanır.

3. Kariyer bağlılı̆̆ı; başarma ihtiyacının bir uzantısı şeklinde düşünülebilir, başarma ihtiyacı yüksek olan insanlarda kariyere bağlılık önemlidir.

\section{Araştırma}

$\mathrm{Bu}$ bölümde araştırmanın önemi ve amacı, örneklem yöntemi ve veri toplama araçlarına ilişkin açılamalar, araştırmadaki hipotezler ve araştırmanın modeli konusunda bilgiler verilmektedir.

\section{Araştırmanın Önemi ve Amacı}

Sağllk hizmetleri; kendisine has özelliği gereği ertelenemez bir hizmettir (Çankaya, 2017; Tengilimoğlu vd., 2018). Bu hizmetlerin, ihtiyaç duyan bireylere, arzu ettikleri kalite düzeyinde en 
kolay ulaşabilecekleri şekilde verilebilmesi amacıyla sağlık sektörü içerisinde yer alan tüm aktörler çok büyük çaba sarf etmektedirler. Özellikle de günümüzde küresel ölçekteki yaygınlığı hızla artan ve bilimsel anlamda "COVID-19" olarak adlandırılan "koronavirüs-2019 salgını"na karşı verilen mücadele, sağlık çalışanlarının görevlerini yaparken ne büyük fedakarlıklar yaptıklarını tüm gerçekliği ile göstermektedir. Sağlık sektörü içerisinde yer alan kadın çalışanlar da bu uğurda emsalsiz bir emek vermektedirler.

Alanyazın taramasında sağlık sektörünün "koruyucu melekleri" olan kadın çalışanların kültürel değer algılarını, kariyer memnuniyetlerini ve kariyer bağlılıklarını ölçen bilimsel bir çalışmaya rastlanılmamıştır. Alandaki bu eksikliği gidermek adına Çankırı ilindeki kamuya ait sağlık kurumlarında görev yapan ve anket çalışmasına gönüllü olarak katılmayı kabul eden kadın sağlık çalışanları ile bu araştırmanın yapılması yararlı görülmüştür.

Çalışmanın temel amacı; kadın sağlık çalışanlarındaki kariyer memnuniyetinin, kültürel değer algıları ile kariyer bağlılıkları arasındaki ilişkide anlamlı bir aracılık etkisinin olup olmadığını tespit etmektir. Ancak bu temel amacın dışında çalışmanın birçok başka amacı da bulunmaktadır. Araştırmadaki diğer amaçları şu şekilde sıralayabiliriz:

- Kadın sağlık çalışanlarının kültürel değerler, kariyer memnuniyeti ve kariyer bağl1lığı düzeylerini tespit etmek,

- Kadın sağlık çalışanlarının kültürel değerler, kariyer memnuniyeti ve kariyer bağlılığı algıları arasında anlamlı ilişkiler olup olmadığını tespit etmek,

- Kadın sağlık çalışanlarının kültürel değerler algılarının kariyer bağlılığı algılarına anlamlı bir etkisinin olup olmadığını tespit etmek,

- Kadın sağlık çalışanlarının kültürel değerler algılarının kariyer memnuniyeti algılarına anlamlı bir etkisinin olup olmadığını tespit etmek.

\section{Araştırmanın Örneklemi ve Veri Toplama Araçları}

Araştırma; Çankırı İl merkezindeki kamuya ait sağlık kuruluşlarında görev yapan kadın sağlık çalışanları ile yapılmıştır. Örnekleme yöntemi olarak tesadüfi olmayan örnekleme yöntemlerinden biri olan yargısal örnekleme yöntemi kullanılmıştır. Anket çalışması 7-25 Ekim 2019 tarihleri arasında gerçekleştirilmiştir. Araştırma örneklemini; ankete katılmayı kabul eden 184 kadın sağlık çalışanı oluşturmaktadır.

Araştırmada 3 farklı veri toplama aracı kullanılmıştır. Bu araçlar sırasıyla; bireysel kültürel değerler, kariyer memnuniyeti ve kariyer bağlılı̆̆ ölçekleridir. Araştırmada, ölçeklerde yer alan ifadelere ek olarak katılımcıların demografik özelliklerini ortaya koyan yedi maddelik soru seti de bulunmaktadır. Araştırmada kullanılan ölçeklere ilişkin bilgiler şu şekildedir:

Bireysel Kültürel Değerler Ölçeği: Hofstede tarafından geliştirilen toplumsal düzeydeki kültürel değerler ölçeği, Yoo, Donthu ve Lenartowicz'in (2011) tarafindan bireysel bağlamda ele alınmıştır. Ölçeğin Türkçeye uyarlanması ile geçerlik ve güvenirlik analizleri gibi işlemler, Saylık' In (2017) doktora tez çalışmasında yapılmış ve çalışma sonucunda 26 maddeden ve 5 boyuttan oluşan "Bireysel Kültürel Değerler Ölçeği” oluşturulmuştur. Ölçeğin KMO değeri ,816 olup; ölçekte yer alan beş faktör, toplam varyansın \%57,53'ünü açıklmakatadır. Saylık (2019) tarafindan ölçeğe güvenilirlik analizi yapılmış ve ölçeğin Cronbach alfa katsayısı 0,800 olarak bulunmuş ve ölçeğin güvenilir olduğu belirtilmiştir. Ölçekteki boyutlardan güç mesafesi ve belirsizlikten kaçınma boyutları 5'er ifade, kolektivizm ve uzun erimlilik boyutları 6'şar ifade ve erillik boyutu ise 4 ifadeden oluşmaktadır. 5'li likert tipindeki ölçeğin geçerli ve güvenilir olduğu ve ayrıca başta eğitim, işletme, sosyoloji, sosyal psikoloji gibi kültürler arası çalışmalara ilişkin bilimsel araştırmalarda kullanılması Saylık (2019) tarafından önerilmiştir. 
Kariyer Memnuniyeti Ölçeği: Greenhaus vd. (1990) tarafından geliştirilen 5 madde ve tek boyuttan oluşan ölçek, Kaya' nın (2018) doktora tezinden alınmıştır. Kaya, tarafından ölçeğe güvenilirlik analizi yapılmış ve ölçeğin Cronbach alfa katsayısı 0,873 olarak bulunmuştur. Kaya (2018), 5'li likert tipindeki kariyer memnuniyeti ölçeğinin güvenilir olduğunu belirtmiştir.

Kariyer Bağlılığı Ölçeği: Kanungo (1982) tarafindan geliştirilen ölçek, Kaya (2018) tarafından doktora tezinde kullanılmıştır. Ölçek, 5 madde ve tek boyuttan oluşmaktadır. Kaya, tarafından ölçeğe güvenilirlik analizi yapılmış ve ölçeğin Cronbach alfa katsayısı 0,829 olarak bulunmuştur. Kaya (2018), 5'li likert tipindeki kariyer bağl1lı̆̆ ölçeğinin güvenilir olduğunu belirtmiștir.

\section{Araştırmanın Hipotezleri}

Araştırmada ilk olarak bağımsız değişken olarak belirlenen kültürel değerler ölçeğinin boyutları ile bağımlı değişken olarak seçilen kariyer bağlılığı arasında anlamlı ilişkiler olup olmadığına yönelik 5 hipotez geliştirilmiştir. Bunu takiben yine bağımsız değişken olan kültürel değerler ölçeğinin boyutları ile aracı değişken olarak belirlenen kariyer memnuniyeti arasında anlamlı ilişkiler olup olmadığına yönelik 5 hipotez daha geliştirilmiştir. Daha sonra aracı değişken olarak belirlenen kariyer memnuniyeti ile bağımlı değişken olarak seçilen kariyer bağl1lığı arasında anlamlı bir ilişki olup olmadığa yönelik bir hipotez dada oluşturulmuştur. Son olarak aracı değişken olarak belirlenen kariyer memnuniyetinin, kültürel değerler ile kariyer bağlılı̆g arasındaki ilişkide anlamlı bir aracılık etkisi olup olmadığına yönelik çalışmanın da temel amacını oluşturan hipotez geliştirilmiştir. Araştırmada incelenen değişkenler göz önünde bulundurularak oluşturulan hipotezleri şu şekilde sıralamak mümkündür: vardir

H1a: Kültürel değerlerin güç mesafesi boyutu ile kariyer bağlılı̆̆

H1b: Kültürel değerlerin belirsizlikten kaçınma boyutu ile kariyer bağlılı̆̆ arasında anlamlı bir ilişki vardır. vardir.

H1c: Kültürel değerlerin kolektivizm boyutu ile kariyer bağl1lığı arasında anlamlı bir ilişki

H1d: Kültürel değerlerin uzun erimlilik boyutu ile kariyer bağ lılığı arasında anlamlı bir ilişki vardir.

H1 e: Kültürel değerlerin erillik boyutu ile kariyer bağlılığı arasında anlamlı bir ilişki vardır.

H2a: Kültürel değerlerin güç mesafesi boyutu ile kariyer memnuniyeti arasında anlamlı bir ilişki vardır.

H2b: Kültürel değerlerin belirsizlikten kaçınma boyutu ile kariyer memnuniyeti arasında anlamlı bir ilişki vardır. ilişki vardır.

H2c: Kültürel değerlerin kolektivizm boyutu ile kariyer memnuniyeti arasında anlamlı bir ilişki vardır.

H2d: Kültürel değerlerin uzun erimlilik boyutu ile kariyer memnuniyeti arasında anlamlı bir

H2e: Kültürel değerlerin erillik boyutu ile kariyer memnuniyeti arasında anlamlı bir ilişki vardir.

H3: Kariyer memnuniyeti ile kariyer bağlılı̆̆ arasında anlamlı bir ilişki vardır.

H4: Kariyer memnuniyetinin, kültürel değerler ile kariyer bağ 11 lı̆̆ arasındaki ilişki üzerinde aracılık etkisi vardır. 


\section{Araştırmanın Modeli}

Araştırmanın amacı doğrultusunda oluşturulan araştırma modeli şu şekildedir:

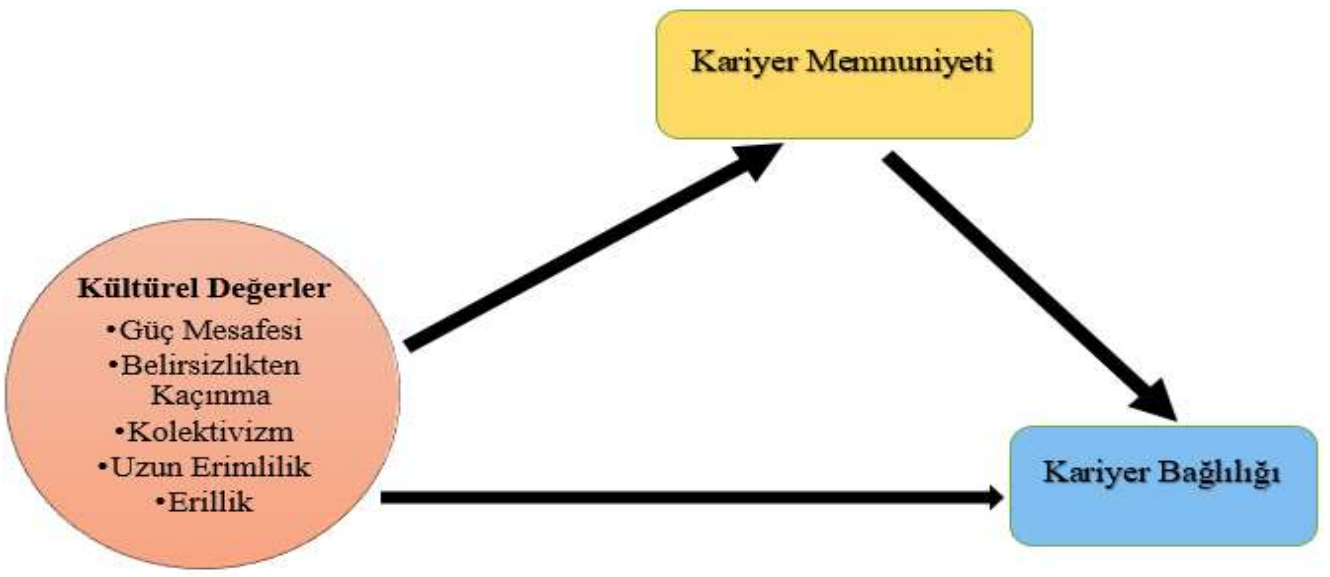

Şekil-7. Araştırmanın Modeli

\section{Bulgular}

$\mathrm{Bu}$ bölümde katılımcılara ilişkin demografik bilgiler, ölçeklere ilişkin güvenilirlik analizi, faktör analizi, korelasyon ve regresyon analizleri ile bu analizlerden elde edilen bulgulara yer verilmektedir.

\section{Tanımlayıcı İstatistiksel Bulgular}

Katılımcılara ilişkin yaş, kurum kıdemi, mesleki kıdem, eğitim düzeyi, meslek, aylık gelir düzeyi ve aylık geliri yeterli bulup bulmadığı gibi konulardaki bulgular Tablo 1'de frekans ve yüzdelik değerleri ile gösterilmektedir.

Tablo 1: Katılımcılara İlişkin Demografik Özellikler ( $\mathrm{N}=184)$

\begin{tabular}{|c|c|c|c|c|c|}
\hline Değisskenler & $\mathbf{N}$ & $\%$ & Değiskenler & $\mathbf{N}$ & $\%$ \\
\hline \multicolumn{3}{|l|}{ Yaș } & \multicolumn{3}{|l|}{ Meslek } \\
\hline 20’den küçük & 28 & 15,2 & Hekim & 22 & 12,0 \\
\hline $20-29$ & 72 & 39,1 & Hemşire & 40 & 21,7 \\
\hline $30-39$ & 52 & 28,3 & Ebe & 12 & 6,5 \\
\hline 40 ve üzeri & 32 & 17,4 & Tibbi Sekreter & 15 & 8,2 \\
\hline \multicolumn{3}{|l|}{ Kurum Kidemi } & Diğer Sağlık Personeli & 32 & 17,4 \\
\hline 1 y1ldan az & 43 & 23,4 & İdari Personel & 36 & 19,5 \\
\hline $1-5 \mathrm{y} 1 \mathrm{l}$ & 66 & 35,8 & Teknik Hizmet Personeli & 12 & 6,5 \\
\hline $6-10$ y1l & 45 & 24,4 & Diğer Personel & 15 & 8,2 \\
\hline 11 yil ve üzerinde & 30 & 16,4 & \multicolumn{3}{|l|}{ Aylık Gelir Düzeyi } \\
\hline \multicolumn{3}{|l|}{ Mesleki Kıdem } & 2.000 TL'den az & 27 & 14,7 \\
\hline 1 yildan az & 24 & 13,0 & $2.000-3.500 \mathrm{TL}$ & 34 & 18,5 \\
\hline $1-5 \mathrm{y} 1 \mathrm{l}$ & 70 & 38,0 & $3.501-5.000 \mathrm{TL}$ & 73 & 39,7 \\
\hline $6-10$ y1l & 52 & 28,3 & $5.001-6.500 \mathrm{TL}$ & 26 & 14,1 \\
\hline 11 yil ve üzerinde & 38 & 20,7 & 6.501 TL ve üzeri & 24 & 13,0 \\
\hline \multicolumn{3}{|l|}{ Eğitim Düzeyi } & \multicolumn{3}{|c|}{ Geliri Yeterli Bulma Durumu } \\
\hline İlköğretim & 14 & 7,6 & Çok Yetersiz & 22 & 12,0 \\
\hline Lise & 34 & 18,5 & Yetersiz & 66 & 35,8 \\
\hline Önlisans & 52 & 28,3 & Ne Yeterli Ne de Yetersiz & 52 & 28,3 \\
\hline Lisans & 72 & 39,1 & Yeterli & 34 & 18,5 \\
\hline Lisansüstü & 12 & 6,5 & Oldukça Yeterli & 10 & 5,4 \\
\hline
\end{tabular}


Tablo 1'e göre; araştırmaya katılanların \%39,1'inin 20-29 yaş aralığında, \%35,8'inin 1-5 y1l arasında kurum kıdemine sahip, \%38'inin 1-5 y1l arasında mesleki deneyime sahip, \%39,1'inin lisans bölümlerinin birinden mezun, \%21,7'sinin hemşire, \%39,7'sinin aylık 3.501-5.000 TL arasında aylık gelire sahip ve \%35,8'inin gelirini yetersiz bulduğu bulgularına ulaşılmıştır.

\section{Güvenirlilik Analizi}

Araştırmada kullanılan ölçeklerin güvenirliliği Cronbach Alpha katsayısı ile test edilmiştir. Araştırmada kullanılan ölçekler ve boyutlarına ait güvenirlilik değerleri Tablo 2'de gösterilmektedir.

Tablo 2: Ölçeklerin Güvenirlilik Katsayıları

\begin{tabular}{l|c|c}
\hline Ölçekler ve Boyutları & Soru Sayısı & Cronbach's Alpha \\
\hline Kültürel değerler Ölçeği (Genel) & 26 &, 849 \\
\hline Güç Mesafesi Boyutu & 5 &, 721 \\
\hline Belirsizlikten Kaçınma Boyutu & 5 &, 866 \\
\hline Kolektivizm Boyutu & 6 &, 779 \\
\hline Uzun Erimlilik Boyutu & 6 &, 821 \\
\hline Erillik Boyutu & 4 &, 736 \\
\hline Kariyer Memnuniyeti & 5 &, 851 \\
\hline Kariyer Bağlılığı & 5 &, 745 \\
\hline
\end{tabular}

Sosyal bilimlerdeki araştırmalarda kullanılan ölçeklerdeki Cronbach's Alpha $(\alpha)$ katsayıları 0,70 'in üzerinde olduğunda kabul edilebilir düzeyde güvenilir, 0,80 'in üzerinde olduğunda ise yüksek düzeyde güvenilir oldukları belirtilmektedir (İslamoğlu ve Alnıaçık, 2013). Tablo 2'ye göre kültürel değerler ölçeği (genel), belirsizlikten kaçınma ve uzun erimlilik boyutları ile kariyer memnuniyeti ölçeği yüksek düzeyde güvenilirliğe sahiptir $(\alpha>0,80)$. Kültürel değerler ölçeğinin güç mesafesi, kolektivizm ve erillik boyutları ile kariyer bağlılığı ölçeği de kabul edilebilir güvenilir düzeylerinde güvenirliliğe sahiptir $(\alpha>0,70)$. Böylelikle çalışmada kullanılan tüm ölçeklerin ve boyutların güvenilir olduğu bulgusuna ulaşılmıştır.

\section{Faktör ve Korelasyon Analizi}

Çalışmada elde edilen verilerin faktör analizine uygun olup olmadığı Kaiser-Meyer-Olkin (KMO) örneklem yeterlilik katsayısı ile analiz edilmiştir. Analiz sonucunda KMO değerlerinin 0,50'nin üzerinde olması nedeniyle verilerin faktör analizi için yeterli olduğu bulgusuna ulaşılmıştır. Ayrıca Bartlett's Test istatistiğine göre değiş̧kenler arasında yüksek korelasyon olduğu ve veri setinin faktör analizi için elverişli olduğu $(\mathrm{p}<0,001)$ bulunmuştur. Tablo 3 'de her bir ölçeğin açıklayıcı faktör analizi sonuçları gösterilmektedir.

Tablo 3: Açıklayıcı Faktör Analizi

\begin{tabular}{|c|c|c|c|c|}
\hline Değişkenler & $\begin{array}{l}\text { Faktör } \\
\text { Yükleri }\end{array}$ & KMO & $\begin{array}{l}\text { Barlett's } \\
\text { Test }\end{array}$ & $\begin{array}{l}\text { Açıklanan } \\
\text { Varyans }\end{array}$ \\
\hline Güç Mesafesi & & & & \\
\hline $\begin{array}{l}\text { Üsst makamlarda çalışanlar, } \\
\text { danışmadan almalıdırları }\end{array}$ &, 815 & \multirow{5}{*}{,669 } & \multirow{5}{*}{,000 } & \multirow{5}{*}{25,214} \\
\hline $\begin{array}{l}\text { Üstlerin, alt makamlarda çalışanların fikirlerine çok } \\
\text { sık başvurmalarıa gerek yoktur. }\end{array}$ & ,850 & & & \\
\hline $\begin{array}{l}\text { Üst makamlarda çalışanlar, alt makamlarda } \\
\text { çalışanlarla yüz göz olmaktan kaçınmalıdır. }\end{array}$ & ,620 & & & \\
\hline $\begin{array}{l}\text { Alt makamlarda çalışanlar, üst makamların kararlarına } \\
\text { karşı gelmemelidir. }\end{array}$ & ,601 & & & \\
\hline $\begin{array}{l}\text { Üst makamlarda çalışanların, alt makamlara yetki } \\
\text { aktarımı yalnızca önemsiz konularla sınırlı olmalıdır. }\end{array}$ & ,763 & & & \\
\hline Belirsizlikten Kaçınma & & & & \\
\hline
\end{tabular}




\begin{tabular}{|c|c|c|c|c|}
\hline $\begin{array}{l}\text { Benden tam olarak ne istendiğini bilebilmem için açık } \\
\text { biçimde belirtilen talimatlar gereklidir. }\end{array}$ & ,771 & \multirow{5}{*}{,669 } & \multirow{5}{*}{, 000} & \multirow{5}{*}{,496 } \\
\hline $\begin{array}{l}\text { Talimatları ve prosedürleri sık1 sıkıya takip etmek } \\
\text { önemlidir. }\end{array}$ & ,647 & & & \\
\hline $\begin{array}{l}\text { Kurallar ve düzenlemeler benden ne beklendiğini } \\
\text { anlamamı sağladığ için önemlidir. }\end{array}$ & ,638 & & & \\
\hline $\begin{array}{l}\text { İşimde kullanmam } \text { gereken } \\
\text { standartlaştırılmasını yararlı buluyorum. }\end{array}$ & ,771 & & & \\
\hline $\begin{array}{l}\text { Yapılacak uygulamaların talimatlarla açıklanması } \\
\text { önemlidir. }\end{array}$ & ,836 & & & \\
\hline \multicolumn{5}{|l|}{ Kolektivizim } \\
\hline $\begin{array}{l}\text { Bireyler kişisel çıkarlarını ait oldukları grup için feda } \\
\text { etmelidirler. }\end{array}$ & ,643 & \multirow{6}{*}{,669 } & \multirow{6}{*}{,000 } & \multirow{6}{*}{9,088} \\
\hline $\begin{array}{l}\text { Zorluklara rağmen bireyler içinde olduğu gruba bağlı } \\
\text { kalmayı sürdürmelidirler. }\end{array}$ & ,728 & & & \\
\hline Grubun iyiliği kişisel ödüllerden daha önemlidir. & ,780 & & & \\
\hline Grubun başarısı bireysel başarıdan daha önemlidir. & ,705 & & & \\
\hline $\begin{array}{l}\text { Bireyler, ancak grubun iyiliği sağlandıktan sonra } \\
\text { kişisel hedeflerinin peşinden gitmelidirler. }\end{array}$ & ,622 & & & \\
\hline $\begin{array}{l}\text { Bireysel hedeflerin gerçekleşmemesi pahasına, birey } \\
\text { grubuna sadık kalmalıdır. }\end{array}$ & ,617 & & & \\
\hline \multicolumn{5}{|l|}{ Uzun Erimlilik } \\
\hline $\begin{array}{l}\text { İnsan sahip olduğu parayı iyi yönetmeli ve dikkatli } \\
\text { harcamalıdır. }\end{array}$ & ,846 & \multirow{6}{*}{,669 } & \multirow{6}{*}{, 000} & \multirow{6}{*}{6,969} \\
\hline $\begin{array}{l}\text { Bütün engellere rağmen amaçlar doğrultusunda } \\
\text { kararll11kla yola devam edilmelidir. }\end{array}$ & ,799 & & & \\
\hline Uzun vadeli planlama yapmak önemlidir. & ,695 & & & \\
\hline Bireylerin kararlı ve istikrarlı olmaları önemlidir. &, 650 & & & \\
\hline $\begin{array}{l}\text { Gelecekte başarılı olmak için, gününü gün etmekten } \\
\text { kaçınılmalıdır. }\end{array}$ & ,627 & & & \\
\hline İleride başarılı olmanın anahtarı çok çalışmaktır. & ,644 & & & \\
\hline \multicolumn{5}{|l|}{ Erillik } \\
\hline $\begin{array}{l}\text { Erkekler için profesyonel bir kariyere sahip olmak } \\
\text { kadınlara kiyasla daha önemlidir. }\end{array}$ & ,782 & \multirow{4}{*}{,669 } & \multirow{4}{*}{, 000} & \multirow{4}{*}{5,835} \\
\hline $\begin{array}{l}\text { Erkekler problemleri mantıkla, kadınlar ise sezgiyle } \\
\text { çözerler. }\end{array}$ & ,783 & & & \\
\hline $\begin{array}{l}\text { Zor problemleri çözebilmek, erkeklerin yaptığı gibi } \\
\text { aktif ve zorlayıcı olmayı gerektirir. }\end{array}$ & ,607 & & & \\
\hline $\begin{array}{l}\text { Erkeklerin kadınlara göre her zaman daha iyi } \\
\text { yaptıkları bazı işler bulunmaktadır. }\end{array}$ & ,650 & & & \\
\hline \multicolumn{5}{|l|}{ Kariyer Memnuniyeti } \\
\hline Kariyerimde elde ettiğim başarılardan memnunum. & ,765 & \multirow{4}{*}{,686 } & \multirow{4}{*}{, 000} & \multirow{4}{*}{63,340} \\
\hline $\begin{array}{l}\text { Tüm kariyer hedeflerime ulaşma yönünde gösterdiğim } \\
\text { gelişmeden memnunum. }\end{array}$ & ,849 & & & \\
\hline $\begin{array}{l}\text { Gelir hedeflerime ulaşma yönünde gösterdiğim } \\
\text { gelişmeden memnunum. }\end{array}$ &, $\mathbf{8 1 6}$ & & & \\
\hline $\begin{array}{l}\text { Terfi hedeflerime ulaşma yönünde gösterdiğim } \\
\text { gelişmeden memnunum }\end{array}$ &, $\mathbf{8 1 0}$ & & & \\
\hline
\end{tabular}




\begin{tabular}{|c|c|c|c|c|}
\hline $\begin{array}{l}\text { Yeni yetenekler geliştirme hedeflerime ulaşma } \\
\text { yönünde gösterdiğim gelişmeden memnunum }\end{array}$ & ,734 & & & \\
\hline Kariyer Bağlılığı & & & & \\
\hline $\begin{array}{l}\text { Başıma gelen en önemli şeyler kariyerimle ilgili } \\
\text { olanlardır. }\end{array}$ & ,600 & \multirow{5}{*}{,713 } & \multirow{5}{*}{,000 } & \multirow{5}{*}{50,940} \\
\hline Bana göre kariyer sadece benim küçük bir parçamdır. & ,619 & & & \\
\hline Kariyerimle yakından ilgiliyimdir. & ,759 & & & \\
\hline $\begin{array}{l}\text { İlgi alanlarımın çoğunluğunu kariyerimle } \\
\text { konular oluşturur. }\end{array}$ & ,850 & & & \\
\hline Çoğunlukla kariyere odaklanmaktan hoşlanırım. & ,711 & & & \\
\hline
\end{tabular}

Açıklayıcı faktör analizi sonucunda kültürel değerler ölçeği toplamda 5 boyut ve 26 ifadeden oluşmaktadır. Kariyer memnuniyeti ve kariyer bağlılığı ölçekleri ise tek boyut ve 5'er ifadeden oluşmaktadırlar. Kültürel değerler ölçeği boyutları toplam varyansın \%58,602'sini, kariyer memnuniyeti ölçeği toplam varyansın \%63,340'ını ve kariyer bağl1lığ ölçeği de toplam varyansın \%50,940'ını açıklamaktadır. Bu bulgulara göre ölçekler ve boyutlarının geçerli ve güvenilir olduğuna karar verilmiştir.

\section{Diğer Analizler}

Araştırmada ilk olarak, 184 kadın sağlık çalışanının kültürel değerler, kariyer memnuniyeti ve kariyer bağ 1 ll $\breve{g ̆}_{1}$ konularındaki algı düzeyleri incelenmiştir. Ölçekler ile ilgili ortalama ve standart sapma değerleri Tablo 4' de gösterilmektedir.

Tablo 4: Değişkenlerin Ortalama ve Standart Sapma Değerleri

\begin{tabular}{|l|c|c|}
\hline Değişkenler & Ortalama & St. Sapma \\
\hline Kültürel değerler & $\mathbf{3 , 1 2}$ &, $\mathbf{5 4}$ \\
\hline Güç Mesafesi Boyutu & 2,47 &, 82 \\
\hline Belirsizlikten Kaçınma Boyutu & 3,27 &, 81 \\
\hline Kolektivizm Boyutu & 3,25 &, 86 \\
\hline Uzun Erimlilik Boyutu & 3,52 &, 88 \\
\hline Erillik Boyutu & 2,96 & $\mathbf{8 7}$ \\
\hline Kariyer Memnuniyeti & $\mathbf{2 , 9 8}$ & $\mathbf{7 5}$ \\
\hline Kariyer Bağlılığı & $\mathbf{2 , 9 0}$ & \\
\hline
\end{tabular}

Aritmetik ortalama değerleri hakkında bir yorumda bulunabilmek için alanyazında kabul görmüş (Shukor vd., 2010; Soh vd., 2010; Chang vd., 2011; Akbolat ve Iş1k, 2012; Obeidat vd., 2016; Çankaya, 2017) daha önceki bilimsel çalışmalardan yararlanılmıştır. Bu çalışmalardaki ortalama değerler; 1.00-2,33 aralığında ise "düşük katılım-düşük düzey", 2,34-3,66 aralığında ise "kısmen katılım-orta düzey", 3,67-5.00 aralığında ise "yüksek katılım-yüksek düzey" olarak nitelendirilmektedir.

Tablo 4'e göre; kadın sağlık çalışanlarının kültürel değerler ölçeğinin geneline ilişkin algı ortalamaları; 3,12'dir. Kültürel değerler ölçeğinin boyutlarına ilişkin algı ortalamaları ise sırasıyla; güç mesafesi boyutunda; 2,47, belirsizlikten kaçınma boyutunda; 3,27, kolektivizm boyutunda; 3,25, uzun erimlilik boyutunda; 3,52 ve erillik boyutunda; 2,96 olarak bulunmuştur. Buna göre; kadın sağlık çalışanlarının kültürel değerler ve boyutlarına ilişkin algı ortalamalarının "orta düzey" olduğu tespit edilmiştir $(2,34-3,66)$. Tüm boyutlara ilişkin algılar her ne kadar orta düzeyde tespit edilse de boyutlar arasında en yüksek düzeydeki algının uzun erimlilik boyutunda olduğu görülmektedir $(3,52)$. Bu boyut, bireyin yaşantısındaki olaylara karşı olan tutumları ile ilgiliydi. Bulgulara göre; kadın sağlık çalışanlarının bilhassa azim ve tutumluluk gibi uzun vadeli yönelim erdemlerini diğer kültürel değerlere göre nispeten daha önemli olarak gördükleri söylenebilir. Kadın sağlık çalışanlarında en düşük seviyedeki algı ortalaması ise; güç mesafesi boyutunda olmuştur $(2,47)$. Bir 
toplumda güç mesafesinin düşük olması durumunda; o toplumdaki bireyler arasında gücün dağılımı nispeten daha eşitti. Ayrıca o toplumda sınıf ayırımı ve hiyerarşi de yoktu. Bu bilgiler 1şığında örneklem grubundaki kadın sağlık çalışanlarının sosyal sınıf ayırımı ve hiyerarşi gibi unsurları diğer kültürel değerlere göre nispeten daha az önemli buldukları söylenebilir.

Tablo 4'teki diğer bulgular ise; kadın sağlık çalışanlarının kariyer memnuniyetine ilişkin algı ortlamasının; 2,98 ve kariyer bağlılığına ilişkin algı ortlamasının ise; 2,90 düzeyinde olduğudur. Son tahlilde örneklem grubundaki kadın sağlık çalışanlarının kültürel değerlerin geneli ve tüm boyutları, kariyer memnuniyeti ve kariyer bağlılı̆̆ konularında orta düzeyde algılara sahip oldukları söylenebilir $(2,34-3,66)$.

Araştırmada ele alınan değişkenlerin birbirleri ile olan ilişki düzeyleri ve bu ilişkilerin anlamlı olup olmadığı gibi hususlar, korelasyon analizi ile incelenmiş̧ir. Korelasyon analizine ilişkin sonuçlar Tablo 5' de gösterilmektedir.

Tablo 5: Değişkenlere İlişkin Korelasyon Analizi

\begin{tabular}{|l|c|c|c|c|c|c|c|}
\hline Değişkenler & $\mathbf{1}$ & $\mathbf{2}$ & $\mathbf{3}$ & $\mathbf{4}$ & $\mathbf{5}$ & $\mathbf{6}$ & $\mathbf{7}$ \\
\hline 1.Güç Mesafesi & 1 & & & & & & \\
\hline 2.Belirsizlikten Kaçınma &, 005 & 1 & & & & & \\
\hline 3.Kolektivizm &, 009 & $\mathbf{, 3 5 5} * *$ & 1 & & & & \\
\hline 4.Uzun Erimlilik &,- 087 & $\mathbf{, 5 8 1 * *}$ & $\mathbf{, 4 1 9} * *$ & 1 & & & \\
\hline 5.Erillik &, 090 & $\mathbf{, 1 9 6} * *$ & $\mathbf{, 4 0 4} * *$ & $\mathbf{, 2 8 0} * *$ & 1 & & \\
\hline 6.Kariyer Memnuniyeti & $\mathbf{1 7 5}^{*}$ &,- 029 &,- 085 &,- 019 &, 038 & 1 & \\
\hline 7.Kariyer Bağlılığ 1 & $\mathbf{, 1 8 8} *$ &,- 057 & $\mathbf{, 2 5 3} * *$ &, 086 & $\mathbf{, 1 9 7} * *$ & $\mathbf{3 9 6} * *$ & 1 \\
\hline
\end{tabular}

$* \mathrm{p}<, 05, \quad * * \mathrm{p}<, 01$

Tablo 5'deki korelasyon analizi bulgularına göre; araştırmada ele alınan kültürel değerler bağımsız değişkeninin boyutları ile aracı değişken olarak belirlenen kariyer memnuniyeti ve bağımlı değişken olarak değerlendirilen kariyer bağlılığı değişkenleri arasında anlamlı bazı ilişkilerin olduğu görülmektedir. Buna göre kültürel değerlerin güç mesafesi boyutu; kariyer memnuniyeti $(, 175)$ ve kariyer bağlllığ $(, 188)$ değişkenleri ile "çok zayıf düzeyde", kolektivizm boyutu; kariyer bağlıllı̆ $(, 253)$ değişkeni ile "zayıf düzeyde", erillik boyutu; kariyer bağlılığı $(, 197)$ değişkeni ile "zayıf düzeyde" pozitif yönlü ilişkilere sahiptirler. Son olarak, aracı değişken olan kariyer memnuniyeti ise; bağımlı değişken olan kariyer bağl1lı̆̆ı ile "zayıf düzeyde" $(, 396)$ pozitif yönde anlamlı bir ilişkiye sahiptir.

Kariyer memnuniyetinin, kültürel değerler ile kariyer bağlılı̆̆ 1 arasındaki ilişkide anlamlı bir aracılık etkisinin olup olmadığını belirleyebilmek için Baron ve Kenny (1986) tarafından önerilen üç aşamalı (hiyerarşik) regresyon analizi yapılmıştır. Bu bağlamda ilk olarak, bağımsız değişken (kültürel değerler) ile aracılık etkisinin olduğu düşünülen değişken (kariyer memnuniyeti) arasında regresyon analizinin yapılması ve aralarında anlamlı bir ilişkinin olup olmadığının belirlenmesi gerekmektedir. Daha sonra ikinci aşamada bağımsız değişkenin (kültürel değerler) bağımlı değişken (kariyer bağlılığı) üzerinde anlamlı bir etkisinin olup olmadığı tespit edilmelidir. Üçüncü aşamada ise; aracı değişken (kariyer memnuniyeti), ikinci aşamada kurulan regresyon modeline dahil edildiğinde bağımısız değişkenin (kültürel değerler) bağımlı değişken (kariyer bağlılığı) üzerindeki regresyon katsayısının düşüp düşmediği ve aracı değişkenin bağımlı değişken üzerinde anlamlı bir etkisinin olup olmadığ 1 tespit edilmelidir. Son yapılan analiz sonucunda Eğer bu etki tamamen ortadan kalkıyorsa "Tam Aracılık Etkisi", tamamen ortadan kalkmayıp sadece bir düşüş gerçekleşiyorsa bu durumda da "Kısmi Aracılık Etkisi"nin olduğundan söz edilmelidir. (Kahya, 2013). Hiyerarşik regresyon analizi sonuçları Tablo 6' da gösterilmektedir. 
Tablo 6: Hiyerarşik Regresyon Analizi

\begin{tabular}{|c|c|c|c|c|}
\hline & & Model 1 & Model 2 & Model 3 \\
\hline Değişkenler & & $\begin{array}{c}\text { Kariyer } \\
\text { Memnuniyeti }\end{array}$ & $\begin{array}{l}\text { Kariyer } \\
\text { Bağlılığı }\end{array}$ & $\begin{array}{l}\text { Kariyer } \\
\text { Bağlılığı }\end{array}$ \\
\hline 1.Güç Mesafesi & \multirow{5}{*}{$\begin{array}{c}\text { Kültürel } \\
\text { Değgerler }^{a}\end{array}$} &, $174 *$ &, $187 * *$ &, $168 * *$ \\
\hline 2.Belirsizlikten Kaçınma & &,- 024 &,$- 224 *$ &,$- 222 *$ \\
\hline 3.Kolektivizm & &,- 122 &, $250 * *$ &, 259 \\
\hline 4.Uzun Erimlilik & & ,044 &, 101 & ,098 \\
\hline 5.Erillik & & ,065 &, 095 &, 090 \\
\hline 6.Kariyer Memnuniyeti ${ }^{b}$ & & & &, $141 *$ \\
\hline \multicolumn{5}{|l|}{ 7.Kariyer Bağl1lı̆g ${ }^{\mathrm{c}}$} \\
\hline $\mathrm{F}$ & & 3,608 & 5,724 & 4,984 \\
\hline $\mathrm{R} 2$ & &, 043 &, 139 &, 145 \\
\hline Düzeltilmiş R2 & & ,016 &, 114 &, 116 \\
\hline $\mathrm{P}$ & & ,040* &, $000 * *$ &, $000 * *$ \\
\hline \multicolumn{5}{|c|}{ Tablodaki değerler standardize edilmiş beta'dır. } \\
\hline
\end{tabular}

Tablo 6'da ilk olarak kültürel değerleri temsil eden değişkenlerin aracı değişken olan kariyer memnuniyeti üzerindeki etkileri incelenmiştir. Yapılan çoklu doğrusal regresyon analizinde kültürel değerler değişkeni boyutlarından yalnızca güç mesafesi boyutunun kariyer memnuniyeti üzerinde anlamlı bir etkisinin olduğu görülmektedir $(, 174$ ve $p<0,05)$. Böylelikle bağımsız değişkenin aracı değişken üzerinde etkisi olması gerektiği yönündeki koşul 1 şartının sağlandığı söylenebilir. İkinci analizde ise; kültürel değerler değişkenini temsil eden boyutların kariyer bağlılı̆̆ bağımlı değişkeni üzerindeki etkileri incelenmiştir. Çoklu doğrusal regresyon analizi sonucunda; kültürel değerler değişkenlerinden güç mesafesi $(, 187$ ve $p<0,01)$, belirsizlikten kaçınma, $(-, 224$ ve $p<0,05)$ ve kolektivizm $(, 250$ ve $\mathrm{p}<0,01)$ boyutlarının kariyer bağlılığ 1 üzerinde anlamlı etkilerinin olduğu görülmüştür. $\mathrm{Bu}$ sonuca göre bağımsız değişkenlerin bağımlı değişken üzerinde etkisi olması gerektiği yönündeki koşul 2 şartının da sağlandığı söylenebilir. Son aşamada yapılan çoklu doğrusal regresyon analizinde ise; aracı değişken olan kariyer memnuniyeti bağımsız değişkenlere eklenmiş ve bu bağımsız değişkenlerin kariyer bağlılığı üzerindeki etkileri incelenmiştir. Analiz sonucunda; kültürel değerler değişkenlerinden güç mesafesi $(, 168$ ve $p<0,01)$ ve belirsizlikten kaçınma boyutlarının $(-, 222$ ve $p<0,05)$ kariyer bağlılığı üzerindeki etkilerinin azaldığı görülmüsstür. Bununla birlikte aracı değişken olan kariyer memnuniyetinin kariyer bağl1lı̆̆ üzerinde anlamlı bir etkisinin olduğu görülmüştür $(, 141$ ve $\mathrm{p}<0,05)$. Aracı değişken modele eklendiğinde bağımsız değişkenlerin bağımlı değişken üzerindeki etkisi tamamen bitmemiş ancak azalmıştır. Ayrıca aracı değişkenin de bağımlı değişken üzerinde anlamlı etkisi olmuştur. $\mathrm{Bu}$ nedenle koşul 3 şartlarının sağlanmış olduğunu söylemek mümkündür. Böylelikle yapılan hiyerarşik regresyon analizi sonucunda kariyer memnuniyeti aracı değişkenin kültürel değerlerin kariyer bağl1lı̆̆ ile olan ilişkisinde "kısmi aracılık" etkisinin olduğu sonucuna varılmıştır.

Hiyerarşik regresyon analizi sonucuna göre araştırmanın modeli revize edilmiş ve oluşturulan yeni araştırma modeli Şekil 8'de gösterilmiştir. 


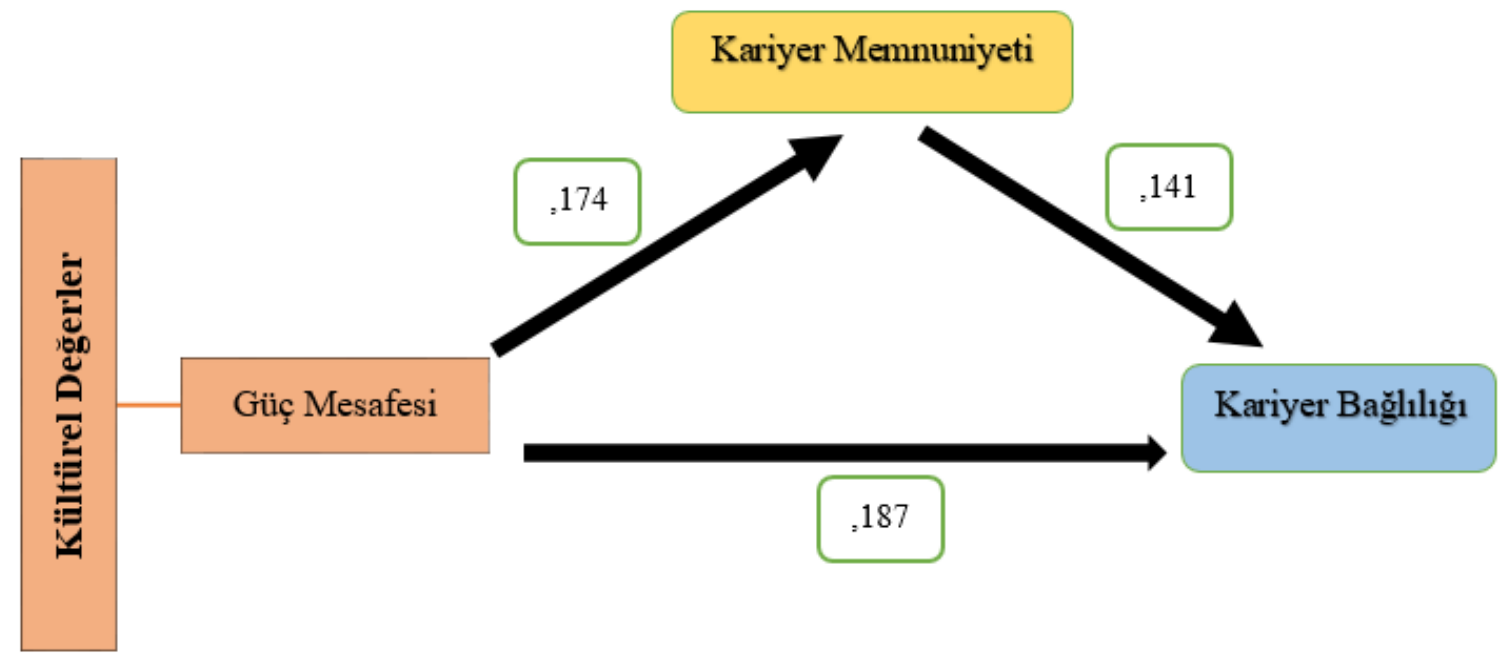

Şekil-8. Rezive Edilen Araştırma Modeli

\section{Sonuç ve Değerlendirme}

Bu araştırma, Çankırı İl merkezindeki kamuya ait sağlık kuruluşlarında görev yapan ve anket çalışmasına gönüllü olarak katılmayı kabul eden 184 kadın sağlık çalışanı ile gerçekleştirilmiştir. Araştırmada kadın sağlık çalışanlarının kültürel değer algıları; bağımsız değişken, kariyer bağlılığı algıları; bağımlı değişken, kariyer memnuniyeti algıları ise; aracı değişken olarak tasarlanmıştır. Temel amacı; kadın sağlık çalışanlarındaki kariyer memnuniyetinin kültürel değerler ile kariyer bağlılığı arasındaki ilişkide anlamlı bir aracılık etkisinin olup olmadığını belirlemek olan bu araştırmanın sonucunda; kariyer memnuniyeti değişkeninin, kültürel değerler ile kariyer bağlılığı arasındaki ilişkide kısmi aracılık etkisine sahip olduğu tespit edilmiştir. Araştırmada ele alınan değişkenler doğrultusunda 12 adet hipotez oluşturulmuştur. Araştırmada kurulan hipotezlerin kabulret durumları Tablo 7'de gösterilmektedir.

Tablo 7: Hipotezlerin Kabul-Ret Durumları

\begin{tabular}{clc}
\hline \multicolumn{1}{c}{ Hipotezler } & Sonuç \\
\hline 1 & $\begin{array}{l}\text { H1a: Kültürel değerlerin güç mesafesi boyutu ile kariyer bağlılı̆̆ı arasında } \\
\text { anlamlı bir ilişki vardır. }\end{array}$ & Kabul \\
\hline 2 & $\begin{array}{l}\text { H1b: Kültürel değerlerin belirsizlikten kaçınma boyutu ile kariyer bağlılığı } \\
\text { arasında anlamlı bir ilişki vardır. }\end{array}$ & Ret \\
\hline 3 & $\begin{array}{l}\text { H1c: Kültürel değerlerin kolektivizm boyutu ile kariyer bağlılı̆̆ı arasında } \\
\text { anlamlı bir ilişki vardır. }\end{array}$ & Kabul \\
\hline 4 & $\begin{array}{l}\text { H1d: Kültürel değerlerin uzun erimlilik boyutu ile kariyer bağlılı̆̆ı arasında } \\
\text { anlamlı bir ilişki vardır. }\end{array}$ & Ret \\
\hline 5 & $\begin{array}{l}\text { H1e: Kültürel değerlerin erillik boyutu ile kariyer bağlılığı arasında anlamlı bir } \\
\text { ilişki vardır. }\end{array}$ & Kabul \\
\hline 6 & $\begin{array}{l}\text { H2a: Kültürel değerlerin güç mesafesi boyutu ile kariyer memnuniyeti arasında } \\
\text { anlamlı bir ilişki vardır. }\end{array}$ & Ret \\
\hline 7 & $\begin{array}{l}\text { H2b: Kültürel değerlerin belirsizlikten kaçınma boyutu ile kariyer memnuniyeti } \\
\text { arasında anlamlı bir ilişki vardır. }\end{array}$ & Ret \\
\hline 8 & $\begin{array}{l}\text { H2c: Kültürel değerlerin kolektivizm boyutu ile kariyer memnuniyeti arasında } \\
\text { anlamlı bir ilişki vardır. }\end{array}$ & $\begin{array}{l}\text { H2d: Kültürel değerlerin uzun erimlilik boyutu ile kariyer memnuniyeti arasında } \\
\text { anlamlı bir ilişki vardır. }\end{array}$ \\
\hline
\end{tabular}




\begin{tabular}{lll}
\hline \hline 10 & $\begin{array}{l}\text { H2e: Kültürel değerlerin erillik boyutu ile kariyer memnuniyeti arasında anlamlı } \\
\text { bir ilişki vardır. }\end{array}$ & Ret \\
\hline 11 & H3: Kariyer memnuniyeti ile kariyer bağlılığı arasında anlamlı bir ilişki vardır. & Kabul \\
\hline 12 & $\begin{array}{l}\text { H4: Kariyer memnuniyetinin, kültürel değerler ile kariyer bağlılığı arasındaki } \\
\text { ilişki üzerinde aracılık etkisi vardır. }\end{array}$ & Kabul \\
\hline
\end{tabular}

Araştırmadaki hipotezlerden; H1a, H1c, H1e, H2a, H3 ve H4 hipotezleri kabul edilirken, $\mathrm{H} 1 \mathrm{~b}, \mathrm{H} 1 \mathrm{~d}, \mathrm{H} 2 \mathrm{~b}, \mathrm{H} 2 \mathrm{c}, \mathrm{H} 2 \mathrm{~d}$ ve H2e hipotezleri reddedilmiştir. Başka bir ifadeyle araştırmadaki hipotezlerin 6's1 kabul edilirken diğer 6's1 ise reddedilmiştir.

Hipotezlere ilişkin görünümü özetlemek gerekirse; araştırmadaki bağımsız değişken olan kültürel değerler boyutlarından güç mesafesi, kolektivizm ve erillik boyutlarının bağımlı değişken kariyer bağlllığı ile anlamlı ilişkilere sahip olduğu ve yine bağımsız değişken olan kültürel değerler boyutlarından yalnızca güç mesafesi boyutunun aracı değişken kariyer memnuniyeti ile anlamlı bir ilişkiye sahip olduğu görülmektedir. Bununla birlikte aracı değişken kariyer memnuniyetinin bağımlı değișken kariyer bağl1lığ ile anlamlı bir ilișkisinin olduğu da elde edilen diğer bir sonuç olarak ortaya çıkmıştır. Son olarak kariyer memnuniyeti değişkeninin, kültürel değerler ile kariyer bağlılığı arasındaki ilişkide kısmi aracılık etkisine sahip olduğu görülmüştür.

Bununla birlikte araştırmadaki temel amacın yanında bazı diğer amaçlar da söz konusu idi. Bunlardan ilki; kadın sağlık çalışanlarının kültürel değerler, kariyer memnuniyeti ve kariyer bağlılığı düzeylerini tespit etmekti. Bu doğrultuda yapılan analizler sonucunda; kadın sağlık çalışanlarının kültürel değerler (genel ölçek) algı ortalaması; 3,12 olarak bulunmuştur. Başka bir ifadeyle kadın sağlık çalışanlarının kültürel değerler algılarının orta düzeyde olduğu sonucuna ulaşıldığını söylemek mümkündür. Tüm boyutlara ilişkin algılar her ne kadar orta düzeyde olsa da boyutlar arasındaki en yüksek düzeydeki algı ortalamasının uzun erimlilik boyutunda olduğu görülmektedir. Bu sonuç; kadın sağlık çalışanlarının bilhassa azim ve tutumluluk gibi uzun vadeli yönelim erdemlerini diğer kültürel değerlere göre nispeten daha önemli buldukları şeklinde yorumlanabilir. Diğer taraftan kültürel değerler boyutları arasında en düșük seviyedeki algı ortalaması ise; güç mesafesi boyutunda olmuştur. Bu sonuç ise; kadın sağlık çalışanlarının sosyal sınıf ayırımı ve hiyerarşi gibi unsurları diğer kültürel değerlere göre nispeten daha az önemli buldukları biçiminde yorumlanabilir.

Araştırmadaki diğer değişkenlerden kariyer memnuniyeti için; 2,98, kariyer bağl1lığı için; 2,90 düzeyinde ortalama değerler tespit edilmiştir. Bu durum araştırmada yer alan kadın sağlik çalışanlarının kariyer memnuniyeti ve kariyer bağlılığı algılarının da orta düzeyde olduklarını göstermektedir.

Dünya nüfusunun yaklaşık yarısı kadınlardan oluşmasına rağmen ekonomik faaliyetlerde kadınlar, erkekler ile aynı oranda temsil olanağı bulamamışlardır. Kadınların toplumsal ve ekonomik hayattaki konumları ülkelerin gelişmişlik düzeyleriyle ilişkilendirilse de tüm toplumlarda kadınların oransal olarak erkeklerin gerisinde kaldıkları bir gerçektir (Akkum ve Ulusoy, 2019). İs hayatında ise kadınlar, eğitim konusundaki eşitsizlikler ile mücadele ederek kendilerine bir yer edinmeye çalışırken, bir başka engel olan işe yerleşmede ve yerleştikleri işlerde yükselmede de bir takım problemlerle karşılaşmaktadırlar. Kadınlar, işlerinde yükselmede kadın erkek ayrımcılığıyla karşılaşabilmektedirler, eşit şartlara sahip olduğu ve belki de daha üstün olduğu bir erkek çalışan, kadın çalışanın planlamış olduğu hedefe daha erken erişme şansına sahip olabilmektedir (Özünlü, 2013). Kadın çalışanların kariyerlerinde karşılaştıkları engellerle mücadele edebilmeleri için kararlı, özgüvenli ve azimli olmaları gerekmektedir (Akgemci vd., 2019). Bu açıdan bakıldığında; bu çalışmadaki kadın çalışanların kariyer memnuniyeti ve kariyer bağlılığı algılarının orta düzeyde çıkması gelecek adına umut vericidir.

Araştırmanın bir diğer amacı da; kadın sağlık çalışanlarının kültürel değerler, kariyer memnuniyeti ve kariyer bağl1lığı algıları arasında anlamlı ilişkiler olup olmadığını tespit etmekti. Bu doğrultuda yapılan korelasyon analizi sonucunda; bağımsız değişken olarak seçilen kültürel değerler 
boyutları ile aracı değişken olarak belirlenen kariyer memnuniyeti ve bağımlı değişken olarak değerlendirilen kariyer bağl1lığı arasında anlamlı bazı ilişkilerin olduğu tespit edilmiştir. $\mathrm{Bu}$ sonuçları şu şekilde özetlemek mümkündür:

\begin{tabular}{|c|c|c|c|c|}
\hline Değişken & İlişki & Değişken & İlişkinin Gücü & İlişskinin Yön \\
\hline Güç mesafesi & & Kariyer memnuniyeti & $(, 175)$; çok zayıf & Pozitif \\
\hline Güç mesafesi & & Kariyer bağ 111 l̆ğ & $(, 188)$; çok zayıf & Pozitif \\
\hline Kolektivizm & & Kariyer bağl1lığ 1 & $(, 253)$; zayıf & Pozitif \\
\hline Erillik & & Kariyer bağ $l_{1} l_{\mathrm{l} g ̆} 1$ & $(, 197)$; zayıf & Pozitif \\
\hline Kariyer memnuniyeti & & Kariyer bağ $\operatorname{ll}_{1} \breve{g ̆ g}_{1}$ & (,396); zayıf & Pozitif \\
\hline
\end{tabular}

Araştırmada kadın sağlık çalışanlarının kültürel değerler ölçeği boyutlarına ilişkin algılarının kariyer bağl1lı̆̆ düzeyleri üzerinde anlamlı bir etkisinin olup olmadığını tespit etmek de başka bir amaç olarak yer almaktaydı. Bu doğrultuda yapılan çoklu doğrusal regresyon analizinde; kültürel değerler ölçeği boyutlarından güç mesafesi $(, 187$ ve $p<0,01)$ ve kolektivizm $(, 250$ ve $p<0,01)$ boyutları kariyer bağlılı̆̆ına pozitif yönde etki ederken, belirsizlikten kaçınma $(-, 224$ ve $p<0,05)$ boyutu ise negatif yönde etki etmektedir. Buna karşın kültürel değerler ölçeğinin uzun erimlilik ve erillik boyutlarının kariyer bağglı l̆ğı üzerinde anlamlı bir etkisinin olmadığ 1 sonucuna varılmıştır.

Araştırmadaki son amaç ise; kadın sağlık çalışanlarının kültürel değerler ölçeği boyutlarına ilişkin algılarının kariyer memnuniyeti düzeyleri üzerinde anlamlı bir etkisinin olup olmadığını tespit etmekti. Bu doğrultuda yapılan çoklu doğrusal regresyon analizinde kültürel değerler ölçeği boyutlarından yalnızca güç mesafesi boyutunun kariyer memnuniyeti üzerinde anlamlı bir etkisinin olduğu $(, 174$ ve $p<0,05)$, diğer boyutların ise herhangi bir anlamlı etkisinin olmadığ sonucuna varılmıştır.

Bu çalışma; sağlık sektöründe görev yapan kadın çalışanların kültürel değerler, kariyer memnuniyeti ve kariyer bağlılığı algılarını ölçen ilk çalışma olması nedeniyle önemli görülmektedir. Ayrıca alanyazında bu üç değişkeni birlikte ele alan başka bir çalışmanın olmaması da alanyazın için ayrı bir zenginlik katacaktır.

Gelecekte, kadın sağlık çalışanlarının kariyer planlaması, cam tavan, boreout ve bornout sendromları gibi örgütsel davranış ile ilgili durumlarını tespit etmeye yönelik akademik çalışmaların hem kamu hem de özel sağlı kuruluşlarında yapılmasının yararlı olacağı düşünülmektedir.

\section{Kaynakça}

Akbolat, M., \& Işık, O. (2012). Hastanelerde Rekabet Stratejileri ve Performans, Atatürk Üniversitesi Sosyal Bilimler Enstitüsü Dergisi, 16(1), 401-424.

Akgemci, T. Çakır, H. Kızıloğlu, E., \& Kalfaoğlu, S. (2019). Kadın Çalışanların İşyerlerinde Karşılaştıkları Kariyer Engelleri Performanslarını ve Örgütsel Özdeşleşme Düzeylerini Etkiler Mi? Bir Alan Araştırması, Journal Of Social, Humanities and Administrative Sciences, 5(19), 800-811.

Akkum, B., \& Ulusoy, H. (2019). Hastane Çalışanlarının Kadın Yöneticilere Karşı Tutumlarının İncelenmesi Sivas ve İstanbul Örneği, Uluslararası Sosyal Araştırmalar Dergisi, 12(68), ss.996-1006. 
Arı, T. (1999). Uluslararası İlişkiler ve Dış Politika, 3. Baskı, İstanbul: Alfa Yayınları.

Armstrong-Stassen, M., \& Cameron, S. (2005). Factors Related to the Career Satisfaction of Older Managerial and Professional Women”. Career Development International, 10(3), 203215.

Arslan, L. (2019). KOBİ'lerde İş Etiği Uygulamaları Üzerine Kültürlerarası Bir Çalışma. Manisa Celal Bayar Üniversitesi Sosyal Bilimler Enstitüsü İşletme Anabilim Dalı Doktora Tezi, Manisa

Asunakutlu, T., \& Safran, B. (2004). Kültürel Farklılıklardan Kaynaklanan Çatışmalara Yönelik Bir Araştırma (Marmaris Turizm Sektörü Örneği). Dokuz Eylül Üniversitesi Sosyal Bilimler Enstitüsü Dergisi, 6(1), 26-49.

Ay, C. (2005). İşletmelerde Etiksel Karar Almada Kültürün Rolü. Yönetim ve Ekonomi, 12(2), 3152.

Aydın, D., \& Uçman, P. (2019). Türk Toplumunun Çalışma Yaşamı Karakteristiklerinin Hofstede'nin Boyutları Çerçevesinde İncelenmesi. Management and Political Sciences Review, 2(2), 131-151.

Baron, R. M. \& Kenny, D. A. (1986) "The Moderator-Mediator Mariable Distinction in Social Psychological Research: Conceptual, Strategic, and Statistical Considerations" Journal of Personality and Social Psychology, 51(6), 1173-1182.

Bayraktar, A. S. (2019). Stratejik İnsan Kaynakları Sürecinde Yetenek Yönetiminin Çalışanların Kariyer Memnuniyetine Etkisi ve Bir Uygulama. Bülent Ecevit Üniversitesi Sosyal Bilimler Enstitüsü İşletme Anabilim Dalı Doktora Tezi, Zonguldak.

Blau, G. (1985). The Measurement and Prediction of Career Commitment. Journal of Occupational Psychology, 58, 277-288.

Bolat, O. İ. (2011). Öz Yeterlilik ve Tükenmişlik İlişkisi: Lider-Üye Etkileşiminin Aracılık Etkisi. Ege Akademik Bakıs, 11(2), 255-266.

Chang, Y. M., Lai, C. T., Lau, A. N., Lee, M. S. \& Tan, G. K. (2011). Factors That Influence Job Performance in Generation Y. Doctoral Dissertation, Universiti Tunku Abdul Rahman.

Çağlar, İ. (2001). Yönetim-Kültür Bağlamında Türk Yönetim Modelinin Saptanmasına Yönelik Kavramsal Bir Çalışma. Gazi Üniversitesi İktisadi ve İdari Bilimler Fakültesi Dergisi, 3(3), 125-148.

Çankaya, M. (2017). Hastane Çalışanlarının Performansa Dayalı Ek Ödeme Sistemine İlişkin Görüşleri Muğla Sitkı Koçman Üniversitesi Eğitim ve Araştırma Hastanesi'nde Bir Araştırma. Sağllk Akademisyenleri Dergisi, 4(4), 272-282.

Çelik, M. (2012). Konaklama İşletmelerinde Algılanan Örgütsel Adaletin Yenilikçi Davranışa Etkisinde Kariyer Memnuniyetinin Aracılık Etkisi. İ̧̧G̈̈Ç Endüstri İlişkileri ve İnsan Kaynaklart Dergisi, 14(2), 99-122.

Çelik, M., Turunç, Ö. \& Bilgin, N. (2014). Lider-Üye Etkileşimi ve Kariyer Memnuniyetinin Yenilikçi Davranışa Etkisinde Etiğin Düzenleyici Rolüne Yönelik Deneysel Bir Araştırma. Mustafa Kemal Üniversitesi Sosyal Bilimler Enstitüsü Dergisi, 11(25), 491508 .

Çelikkol, M. (2019). Ulusal Kültürel Özelliklerin Girişimcilik Üzerine Etkisi ve Ekonomik Gelişmişlik Düzeyi İle Karşılıklı Etkileşimi: Küresel Düzlemde Bir Çalışma. Gebze 
Teknik Üniversitesi Sosyal Bilimler Enstitüsü İşletme Anabilim Dalı Doktora Tezi, Kocaeli.

Dursun, İ. T. (2013). Örgüt Kültürü ve Strateji İlişkisi: Hofstede'nin Boyutları Açısından Bir Değerlendirme. Siyaset, Ekonomi ve Yönetim Araştırmaları Dergisi, 1(4), 43-56.

Farh, J. L., Hackett, R. D., \& Liang, J. (2007). Individual-Level Cultural Values as Moderators of Perceived Organizational Support-Employee Outcome Relationships in China: Comparing The Effects of Power Distance and Traditionality. Academy of Management Journal, 50(3), 715-729.

Greenhaus, J. H., Parasuraman, S., \& Wormley, W. M. (1990). "Effects of Race on Organizational Experiences, Job Performances Evaluations, and Career Outcomes", Academy of Management Journal, 33(1), 64-86.

Güçlü, N. (2003). Örgüt Kültürü, Manas Üniversitesi Sosyal Bilimler Dergisi, 3(6), 147-159.

Hofstede, G. (1991). Cultures and Organizations, Software of the Mind. New York: McGraw-Hill.

Hofstede, G., Hofstede, G. J. \& Minkov, M. (2010). Cultures and Organizations, Software of the Mind, Intercultural Cooperation and Its Importance for Survival. New York: McGrawHill.

İslamoğlu, A. H., \& Alnıaçı, Ü. (2013). Sosyal Bilimlerde Araştırma Yöntemleri (SPSS Uygulamalı). İstanbul: Beta Yayınevi.

Kahya, C. (2013). Örgütsel Sinizm, İş Performansını Etkiler Mi? İş Tatminin Aracılık Etkisi. Küresel İktisat ve İşletme Çalışmaları Dergisi, 2(3), 34-46.

Kang, H. J., Gatling, A., \& Kim, J. (2015). The Impact of Supervisory Support on Organizational Commitment, Career Satisfaction, and Turnover Intention for Hospitality Frontline Employees. Journal of Human Resources in Hospitality \& Tourism, 14(1), 68-89.

Kanungo, R. N. (1982). "Measurement of Job and Work Involvement", Journal of Applied Psychology, 67(3), 341-349.

Karabıyık, İ. (2012). Türkiye'de Çalışma Hayatında Kadın İstihdamı. Marmara Üniversitesi İktisadi ve İdari Bilimler Dergisi, 32(1), 231-260.

Kaya, A. (2018). Kariyer Gelişim Sürecinin Örgütsel Bağlllık ve İșten Ayrılma Niyeti Üzerine Etkisinin Yapısal Eşitlik Modellemesi ile Test Edilmesi. Hitit Üniversitesi Sosyal Bilimler Enstitüsü İşletme Anabilim Dalı Doktora Tezi, Çorum.

Kaya, A. (2019). Örgütlerde Kariyer Gelişim Süreci. Ankara: IKKSAD Yayınevi.

Kılınç, N. Ş. (2015). Küresel Eğilimler Çerçevesinde Kadın İstihdamı. Hak İş Uluslararası Emek ve Toplum Dergisi, 4(9), 120-135.

Küçükkömürler, S., \& Kırımer-Aydınlı, F. (2019). Kadınların İş Yaşamındaki Konumunun Hofstede'nin Kültür Boyutları Açısından İncelenmesi. İş ve İnsan Dergisi, 6(1), 43-53.

Mowday, R.T., Porter, L. W., \& Steers, R. M. (1982). Employee-Organization Linkages. New York Academic Press.

Obeidat, B. Y., Al-Suradi, M. M., \& Tarhini, A. (2016). The Impact of Knowledge Management on Innovation: An Empirical Study on Jordanian Consultancy Firms. Management Research Review. 39(10), 1214-1238. 
Örücü, E., Kılıç, R., \& Kılıç, T. (2007). Cam Tavan Sendromu ve Kadınların Üst Düzey Yönetici Pozisyonuna Yükselmelerindeki Engeller: Balıkesir İli Örneği. Yönetim ve Ekonomi: Celal Bayar Üniversitesi Ikktisadi ve İdari Bilimler Fakültesi Dergisi, 14(2), 117-135.

Özdevecioğlu, M., \& Aktaş, A. (2007). Kariyer Bağl1lığı, Mesleki Bağlılık ve Örgütsel Bağlılı̆̆ın Yaşam Tatmini Üzerindeki Etkisi: İş-Aile Çatışmasının Rolü. Erciyes Üniversitesi Iktisadi ve İdari Bilimler Fakültesi Dergisi, 28, 1-20.

Öztürk, H. K. (2018). Kültürün İ̧̧ Girişimcilik Üzerine Etkisi: Türkiye ve Almanya Örnekleri. Karabük Üniversitesi Sosyal Bilimler Enstitüsü İșletme Anabilim Dalı Doktora Tezi, Karabük.

Öztürk, L., Çiftçi, G. E., \& Hırlak, B. (2017). Kümeleme Analizi Kullanarak Kadının Yaşam Kalitesi ve Profili Açısından İllerin Homojen Kümelere Ayrılması. Gazi Üniversitesi Sosyal Bilimler Dergisi, 4(10), 301-318.

Özünlü, D. (2013). Cam Tavan Sendromunun Örgütsel Bağlllık Üzerindeki Etkisini Ölçmeye Yönelik Bir Araştırma. Dumlupınar Üniversitesi Sosyal Bilimler Enstitüsü İşletme Anabilim Dalı Yüksek Lisans Tezi, Kütahya.

Sargut, S. (1994). Kültürlerarası Farklılaşma ve Yönetim, Ankara: Verso Yayınları,

Saylık, A. (2017). Okul Müdürlerinin Paternalist (Babacan) Liderlik Davranışları İle Hofstede'nin Kültür Boyutları Arasındaki İlişki. Ankara Üniversitesi Eğitim Bilimleri Enstitüsü Eğitim Yönetimi ve Politikası Anabilim Dalı Eğitim Yönetimi ve Teftişi Programı Doktora Tezi, Ankara.

Saylık, A. (2019). Hofstede'nin Kültür Boyutları Ölçeğinin Türkçeye Uyarlanması; Geçerlik ve Güvenirlik Çalışması. Uluslararası Türkçe Edebiyat Kültür Ĕgitim Dergisi, 8(3), 18601881.

Shukor, N. A., Halima, N. D. A., Othmanb, N. \& Khalidb, A. H. (2010). Students' Perception on the Developed Generic Skills in Universiti Teknologi Malaysia. In Proceeding of National Student Development Conference.

Sığrı, Ü., \& Tığl1, M. (2006). Hofstede'nin" Belirsizlikten Kaçınma" Kültürel Boyutunun YönetselÖrgütsel Süreçlerde ve Pazarlama Açısından Tüketici Davranışlarına Etkisi. Marmara Üniversitesi İ̈BF Dergisi, 21(1), 327-342.

Soh, T. M. T., Arsad, N. M. \& Osman, K. (2010). The Relationship of 21st Century Skills on Students' Attitude and Perception Towards Physics. Procedia-Social and Behavioral Sciences, 7, 546-554.

Şimşek, M. Ş., \& Çelik, A. (2012). Çağdaş Yönetim ve Örgütsel Başarım. Konya: Eğitim Yayınevi.

Tengilimoğlu, D., Işık, O., \& Akbolat, M. (2018). Sağlık İşletmeleri Yönetimi, 9. Baskı, Ankara: Nobel Akademik Yayıncılık.

Toruntay, H. T. (2019). Çalışanların, Psikolojik Güçlendirmeye İlişkin Algllarının Performansları Üzerindeki Etkisi: İşveren Çekiciliği Alglsının Aracı ve Hofstede'nin Kültürel Boyutlarının Düzenleyici Rolü Türkiye ve Fransa Alan Araştırmast. İstanbul Ticaret Üniversitesi Sosyal Bilimler Enstitüsü İşletme Anabilim Dalı Doktora Tezi, İstanbul.

Yoo, B., Donthu, N., \& Lenartowicz, T. (2011). Measuring Hofstede's Five Dimensions of Cultural Values at The Individual Level: Development and Validation of CVSCALE. Journal of International Consumer Marketing, 23(3-4), 193-210. 
Yüksel, B. (1989). Kültürel Niteliklerimizin Yönetime Etkileri. Anadolu Üniversitesi İktisadi ve Ídari Bilimler Fakültesi Dergisi, 7(1), 333-347. 